\title{
NEUROPSYCHOPHARMACOLOGY REVIEWS Sex differences in hippocampal cognition and neurogenesis
}

\author{
Shunya Yagi ${ }^{1}$ and Liisa A. M. Galea (iD)
}

Sex differences are reported in hippocampal plasticity, cognition, and in a number of disorders that target the integrity of the hippocampus. For example, meta-analyses reveal that males outperform females on hippocampus-dependent tasks in rodents and in humans, furthermore women are more likely to experience greater cognitive decline in Alzheimer's disease and depression, both diseases characterized by hippocampal dysfunction. The hippocampus is a highly plastic structure, important for processing higher order information and is sensitive to the environmental factors such as stress. The structure retains the ability to produce new neurons and this process plays an important role in pattern separation, proactive interference, and cognitive flexibility. Intriguingly, there are prominent sex differences in the level of neurogenesis and the activation of new neurons in response to hippocampusdependent cognitive tasks in rodents. However, sex differences in spatial performance can be nuanced as animal studies have demonstrated that there are task, and strategy choice dependent sex differences in performance, as well as sex differences in the subregions of the hippocampus influenced by learning. This review discusses sex differences in pattern separation, pattern completion, spatial learning, and links between adult neurogenesis and these cognitive functions of the hippocampus. We emphasize the importance of including both sexes when studying genomic, cellular, and structural mechanisms of the hippocampal function.

Neuropsychopharmacology (2019) 44:200-213; https://doi.org/10.1038/s41386-018-0208-4

\section{INTRODUCTION}

Studying sex differences in various diseases and disorders has become increasingly important as there are sex differences not only in the prevalence of certain diseases but also manifestation of the disease and in treatment efficacy [1-4]. We focus on the importance of studying sex differences in cognition with an eye toward a better understanding of the notable sex differences in the prevalence and severity of memory symptoms in a number of neurological diseases that favor either sex. This research is important as cognitive deficits with neurological disease show significant sex differences.

In both Alzheimer's disease (AD) and depression, women show a greater prevalence of disease and steeper declines in memory or more severe cognitive symptoms in both disorders [1-3,5]. On the other hand, men with schizophrenia or Parkinson's Disease show greater cognitive impairments compared to women with these same diseases [6-11]. Although underlying biological mechanisms of these sex differences in cognitive impairment with neurological disease are not completely elucidated, there are sex and sex hormones differences in hippocampus structure and plasticity that may contribute to the greater vulnerability within each sex by disease type. Understanding sex differences in the contribution of hippocampal plasticity to cognition can give us important clues on the underlying mechanisms of disorders that involve disruptions to cognition and hippocampal integrity in an effort to lead to better treatments for patients with such disorders.

In this review, we focus on sex differences in hippocampal cognition with an emphasis on understanding how sex differences in hippocampal adult neurogenesis may contribute to cognition. However, while we discuss sex differences in behavior and sex differences in the structure and properties of the hippocampus, we do not mean to suggest that sex differences in structure of the hippocampus are the cause of sex differences in behavior. It is equally possible that sex differences in structure may cause or prevent sex differences in behavior [12]. Certainly, there are many types of sex differences noted, including sex differences seen in mechanism but no sex differences seen in behavior [13]. A recurring theme throughout this review though will be that we continue to be bereft of a full understanding of how males and females differ in even a basic understanding of hippocampal structure, connectivity, receptor dynamics, and function.

We concentrate on the hippocampus as it is a highly plastic structure due in part to the presence of adult neurogenesis in the dentate gyrus [14-16], fluctuations in dendritic spine/synapse density, dendritic arbourization [17], and electrophysiological plasticity with long-term potentiation (LTP) and long-term depression (LTD) $[18,19]$. This plasticity is modified in a sex dependent manner either basally or may manifest after exposure to stress or other experiences. The circuitry (reviewed in [20]), and receptor characteristics of the hippocampus are well known, but as mentioned above, an important caveat is that we know little of how these characteristics may differ between males and females.

Importantly, sex differences in the hippocampus, at least in part, relate to steroid hormone manipulations and it is important to acknowledge that the hippocampus contains sex hormone receptors such as androgen receptors (AR), and estrogen receptors (ER)- $a, \beta$ and G-coupled protein receptor (GPER). The relative receptor density differs by sex in a region-specific way as the CA3 and CA4 regions of adult female rats contain a greater amount of ER- $\beta$ compared to male rats [21] whereas there are greater levels of $A R$ in male compared to female rats, dependent on estrous cycle phase in the CA1 and dentate gyrus [22]. Furthermore, there

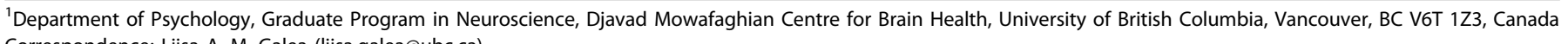
Correspondence: Liisa A. M. Galea (liisa.galea@ubc.ca)

Received: 7 April 2018 Revised: 29 August 2018 Accepted: 30 August 2018

Published online: 7 September 2018 
are notable alterations in females in the distribution of ERa and $\beta$ and progesterone receptors across the estrous cycle [23]. While beyond the scope of this review, there are notable sex differences in AR and ER distribution in the hippocampus during development [24]. Thus, it is important to note that there are sex, age, and estrous cycle phase differences in the level of mRNA and protein expression of these hormone receptors in the hippocampus.

Many of the sex differences in the hippocampus are also seen following exposure to stress, and the hippocampus contains a high concentration of glucocorticoid and mineralcorticoid receptors (MR) compared to other brain regions, which makes the hippocampus more vulnerable to chronic glucocorticoid exposure via stress [25-27]. Although to our knowledge no studies have directly compared the sexes, there are some hints in the literature of sex differences in glucocorticoid receptor (GR) are that women show a statistically significant reduction in GR expression in the hippocampus with age, while men show only a trend for a reduction [28]. However, it is important to note that this study had a relatively small sample size of post-mortem tissue (12 males, 14 females). Sex differences in the pattern of $M R$ and potential changes in GR expression are seen during development in rodents [29]. Unfortunately, the work to categorize sex differences in receptor density characteristics of steroid hormone receptors and other receptors within the hippocampus is not yet complete, and we need to acknowledge that more differences in receptor density and characteristics likely exist between the sexes.

In this review, we note the accumulated evidence for sex differences in the morphology, connectivity, and physiology of the hippocampus in humans and in rodents, then, we discuss sex differences in the hippocampal adult neurogenesis focusing on basal differences and after stress and learning. Lastly, we discuss sex differences in hippocampus-dependent spatial learning and fear conditioning with a focus on strategy use and when sex differences in these tasks are expressed.

Sex differences in the morphology, activation, and connectivity of the hippocampus: findings from human studies

Men typically are reported to have larger volumes of both the left and right hippocampus than women [30] but once total brain volume or intracranial volume is used as a correction factor, there is no longer a significant sex difference [31]. Recent studies show no sex differences in hippocampal volume across development [32]. One caveat in these studies is that a number of factors that influence hippocampal volume are not often documented including early adversity (reductions are often seen in men but not in women: [33]), phase of menstrual cycle [34], parity status [35], hormone therapy [36], menopausal status [37], genotype [38], and testosterone levels in men [39]. Researchers are cautioned that these variables need to be considered to obtain an accurate understanding of sex differences in the volume of the hippocampus.

Whereas whole hippocampal volume may not show a sex difference, regional differences within the hippocampus and connectivity to the hippocampus do exist between the sexes [40, 41]. For example, women have larger posterior hippocampus than men [40], with differences between the sexes in structural covariance and functional connectivity, indicating differences in connectivity. Studies in humans indicate sex differences in functional brain connectivity [42-45]. Women have more interhemispheric connections compared to men, while men have stronger intra-hemispheric connection compared to women [4244]. Furthermore, Filippi et al. [46] showed women have greater intra-connectivity within the temporal lobe compared to men. One study has argued that because there is no true distinct dichotomy between the sexes in terms of MRI measures of volume and connectivity that this suggest there is no true 'male' or 'female' typical brain [45]. But other researchers have argued that the lack of a dichotomy (an extreme form of sex difference) does not preclude the idea that there are patterns of connectivity, and structural differences on a continuum that relate to a maletypical or female-typical brain (see $[47,48]$ for more discussion). fMRI studies in language processing show women have greater bilateral activation of BOLD in the temporal and frontal lobes in comparison to men $[49,50]$. Furthermore, women have greater activation in regions other than the hippocampus compared to men during a virtual water maze task, such as prefrontal cortex $[51,52]$. This is particularly intriguing as it matches animal data indicating a greater involvement of the prefrontal cortex in female rats compared to male rats during the Morris water maze task [53]. These types of studies are important to consider when examining activation patterns without regard to stratifying the data by sex.

Briefly, there are sex differences in neurodegeneration noted in $A D$. The $C A 1$ region of the hippocampus is one of the first sites of damage in $A D$ [54]. Atrophy of the CA1 region in $A D$ and other forms of dementia is associated with memory loss and spatial disorientation during early stages of the disease [55-57]. Sex differences exist in the areas that correlated with AD progress and neuronal density with age in the hippocampus [58]. Negative associations were seen in Alzheimer's patients between Braak stage and CA1 neuronal density in women but not men, while these same associations were seen in the CA3 neuronal density in men but not women [58]. In addition, elevated Braak-stage resulted in decreased in CA1 neuronal density in women, but not in men, whereas elevated Braak stage resulted in decreased CA3 neuronal density in men but not in women. Interestingly, total tau, as well as, A $\mathrm{A}-42$ levels in women were associated with a steeper decline in cognition and volume of the hippocampus compared to men [59] with more pronounced effects in the prodromal condition of mild cognitive impairment $(\mathrm{MCl})$. In addition, in $\mathrm{MCl}$ patients with a higher risk to develop $A D$, women were found to show greater cognitive decline and more total tau, $A \beta-42$ ratios that were exacerbated by the presence of the apolipoprotein e4 allele [60]. Furthermore, studies suggest that women are more likely to show associations of progression to $A D$ with changes in hippocampal volume and amyloid burden, while in men white matter hyperintensities are more related to disease progression $[59,61,62]$. This work is an important step to determine whether sex differences can aid in our understanding of disease progression and possible treatment strategies that may need to differ by sex.

Sex differences in morphology and electrophysiological properties of hippocampal neurons: findings from rodent studies

Sex differences exist in the morphology and electrophysiological properties of hippocampal neurons. However, researchers need to be aware that estrous cycle significantly influences a number of parameters in which sex differences are seen such as cell proliferation [63, 64], hippocampal volume [65], LTP and LTD $[66,67]$, CA1 apical spine density [68], and hippocampal AMPA receptor stoichiometry [69]. Thus, if estrous phase is not taken into consideration this may affect magnitude and appearance of sex differences in these measures. Studies have reported that there are sex differences in the morphology of granule neurons and CA3 pyramidal neurons [70-72]. Juraska et al. [72] found that male rats had greater dendritic intersections in granule neurons of the dentate gyrus compared to female rats. Galea et al. [73] indicated that female rats had greater branch points in the basal dendrites of CA3 pyramidal neurons compared to male rats and Gould et al. [74] found that females had more primary dendrites in CA3 than males, and that males had more thorny excrescences than females. Another study found more dendritic spines in the CA3 pyramidal neurons in females than in males although the sexes were not directly compared statistically in that study [70]. These results suggest basal sex differences in the morphology of granule and pyramidal neurons in the rat hippocampus (see Table 1). 
Table 1. Basal sex differences in hippocampal plasticity

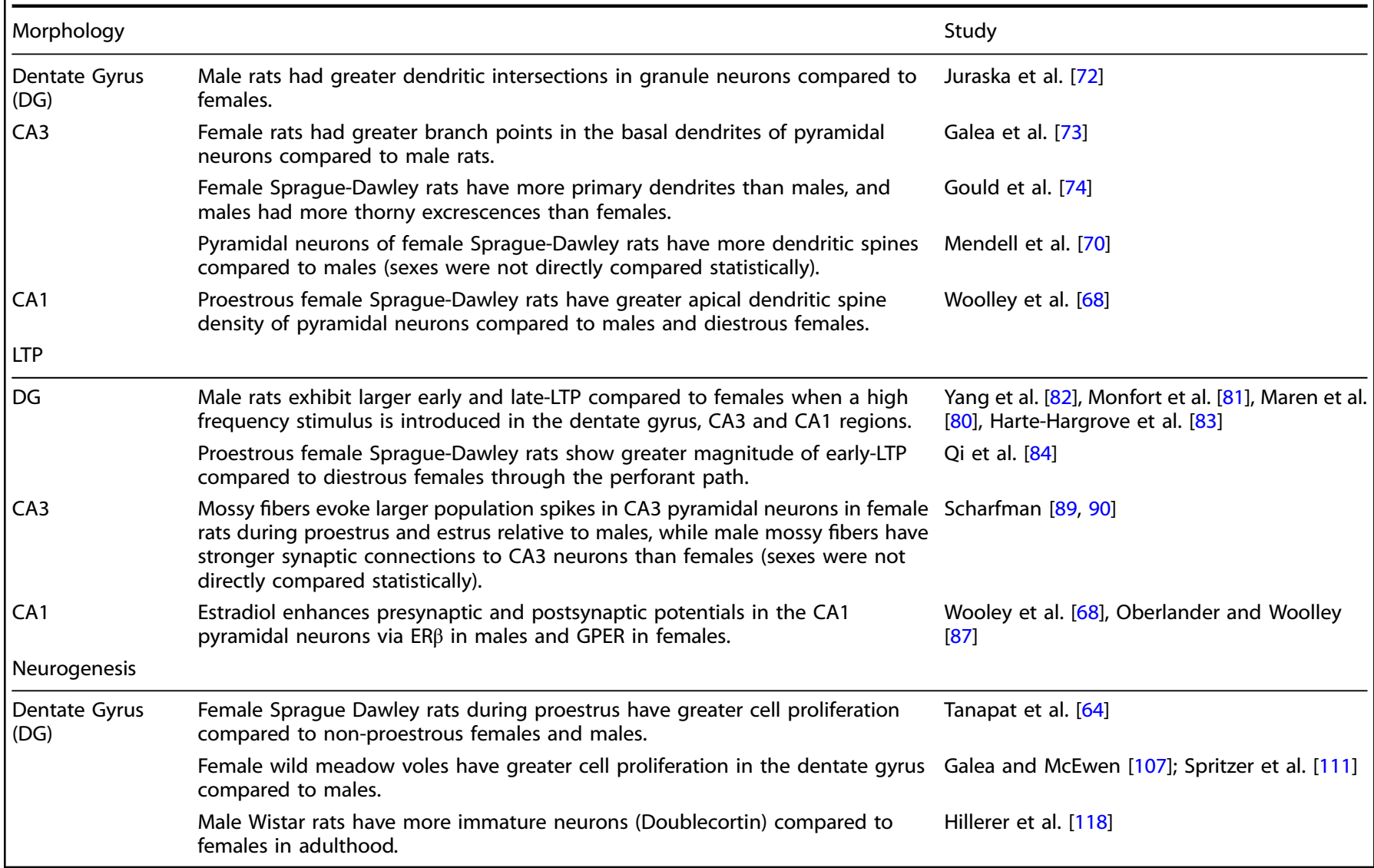

Gonadal hormone manipulations, estrous cycle phase and exposure to stress can also reveal sex and hormone differences in hippocampal morphology [68, 73, 75]. For example, proestrous female rats have greater apical dendritic spine density in CA1 pyramidal neurons compared to males and diestrous females [68]. Acute stress increases apical dendritic CA1 spine density in males but decreases it in females, dependent on estrous cycle phase [75]. Many of the structural differences in the dentate gyrus and CA3 regions show sex differences in response to gonadectomy, with mossy fibers innervations increased in castrated males but not in ovariectomized females [70]. In addition, castrated males have longer dendrites and larger mossy fibers, while ovariectomy decreases dendritic spine density in the CA3 region [70]. However, this study did not directly compare the effects of gonadectomy between the sexes statistically. Chronic stress decreases apical dendritic complexity in male rats, and basal dendritic complexity in female rats in the CA3 region of hippocampus ([73]; see Fig. 1). In the dentate gyrus, granule neurons have greater dendritic intersections in single-housed males than single-housed females, whereas females raised in an enriched environment have larger dendritic trees compared to males raised in an enriched environmental [76]. Intriguingly, much like work in humans, early life adversity reduces hippocampal volume, neurogenesis and impairs spatial memory in male rodents (reviewed in [77]) but separate studies indicate that females show resilience after early life adversity with little effect on the hippocampus [78]. Even though these studies did not directly examine sex differences, a number of studies have corroborated these findings (reviewed in [77]). There are sex differences in the manifestation of early life adversity on the hippocampus and amygdala [79] with males, but not females, showing more morphological changes after various forms of early life stress [79]. These results collectively suggest that sex differences in the morphology of hippocampal subregions exist under basal conditions and that other sex differences are unveiled after environmental or gonadal hormone perturbations (see Table 2).

In addition to the morphological differences, there are sex differences in LTP in the hippocampus. Males exhibit larger early and late-LTP compared to females in the dentate gyrus, CA3 and CA1 regions [80-83]. Interestingly, proestrous females showed greater magnitude of early-LTP compared to diestrous females through the perforant path [84]. It is important to note however, that during proestrus, seizure threshold is also decreased $[85,86]$ and as such, it becomes more difficult to find an appropriate tetanus [66], indicating greater excitability in the female hippocampus during proestrus. Furthermore, the composition of AMPA/NMDA receptors of CA1 pyramidal neurons is different between males and females, as females show greater AMPA/ NMDA ratio than males [81, 84]. Oberlander and Woolley [87] demonstrated that estradiol enhances presynaptic and postsynaptic potentials in the CA1 pyramidal neurons in both males and females. However, postsynaptic sensitivity of male CA1 pyramidal neurons is potentiated by ER $\beta$ while female CA1 pyramidal neurons are potentiated by GPER1 [87]. In addition to sex differences in the CA1 region of hippocampus, there are sex differences in the neural plasticity at DG-CA3 synapses (see [88] for review). In short, mossy fibers evoke larger population spikes in CA3 pyramidal neurons in females during proestrus and estrus relative to males, while male mossy fibers have stronger synaptic connections to CA3 neurons than females $[89,90]$. However, these two studies did not compare males and female directly. These anatomical and electrophysiological findings suggest that intrahippocampal circuitry and ER mechanisms are differently organized between males and females. Furthermore, the female hippocampus is dynamic across the estrous cycle and through 


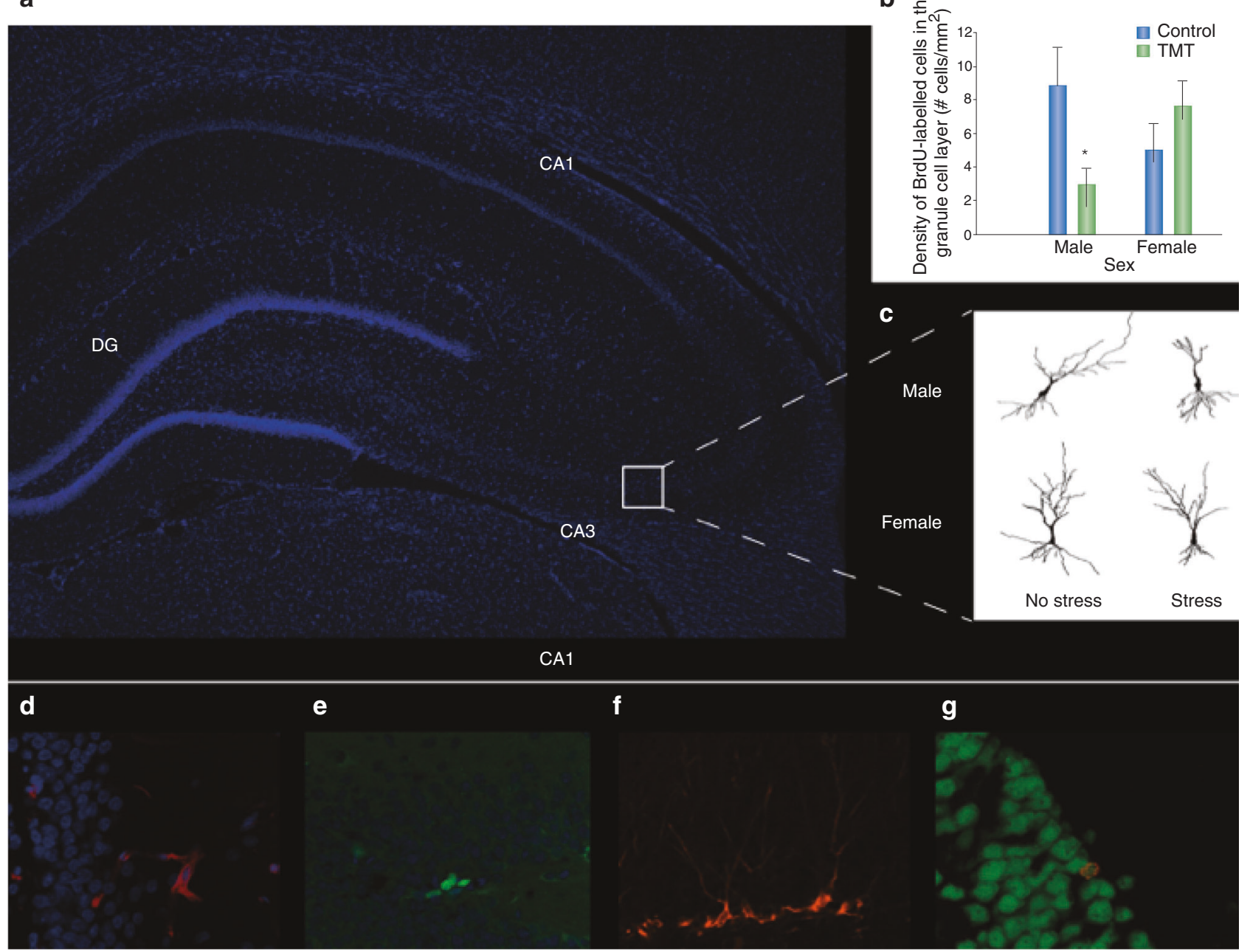

Fig. 1 a Photomicrograph of a coronal section of a rodent hippocampus. b Acute predator odor stress (TMT) decreases cell proliferation in the dentate gyrus of male rats, but not in female rats ([110]; modified from original with permission). c Chronic restraint stress for 21 days decreases apical dendritic complexity in male rats, the same stress decreases basal dendritic complexity in female rats in the CA3 region of hippocampus [73]. Figures are reprinted with permission from Falconer and Galea [110] and Galea et al. [73]. d Neural stem cell marker Nestin-expressing cells (red) in the dentate gyrus merged with DAPI (blue). e Ki67-expressing cells (green) in the dentate gyrus merged with DAPI (blue). f Doublecortin-expressing cells (red) in the dentate gyrus. g Double staining of NeuN (green) and BrdU (red) in the dentate gyrus 3 weeks after BrdU injection. DCX doublecortin, DG dentate gyrus, TMT trimethylthiazoline (main component of fox feces), BrdU bromodeoxyuridine

reproductive experience (for review, see [91]). Further research is needed to elucidate the underlying cellular mechanisms of sex differences in hippocampal physiology under basal and environmental perturbations.

\section{SEX DIFFERENCES IN ADULT NEUROGENESIS IN THE HIPPOCAMPUS}

Adult neurogenesis in the dentate gyrus plays important roles for some forms of learning and the stress response [92-94]. For instance, reduction of hippocampal adult neurogenesis leads to an impairment in trace eye blink conditioning [95], pattern separation [94], contextual fear conditioning [96, 97], proactive interference and forgetting [98-100], long-term, but not short-term, spatial memory [101], and reversal learning [102, 103], although sex differences were not analyzed in these studies. However, one study has noted that the ablation of adult neurogenesis did not influence memory for novel object placement in either male or female rats [104]. It is not known whether there are sex differences in the functional outcome of reducing adult neurogenesis but there are differences in neurogenesis levels after learning and stress that are discussed below.
Net increases or decreases in the amount of neurogenesis are determined by changes in cell proliferation, migration, differentiation, and survival either independently or in orchestration together. Sex differences are seen in some of these responses to manipulations as prenatal alcohol exposure decreases neurogenesis in female, but not male, rats via reduction in the ratio of new cells differentiating into neurons without affecting cell proliferation or survival, although the sexes were not directly compared across studies $[105,106]$. We next discuss basal sex differences in cell proliferation [64, 107], but not survival of these new neurons (see the section 'Sex differences in basal adult neurogenesis'), and in the production and survival of adult-born neurons in response to stress or hippocampus-dependent learning [64, 108-110] in the sections 'Sex differences in adult neurogenesis after exposure to stress' and 'Sex differences in adult neurogenesis after learning' below.

Sex differences in basal adult neurogenesis

Some studies find basal sex differences in cell proliferation but not in survival of new neurons in the dentate gyrus. In Sprague Dawley rats and meadow voles, females have greater levels of cell proliferation compared to males that may depend on phase 
Table 2. Sex differences in hippocampal plasticity revealed after gonadectomy, stress, or learning

\begin{tabular}{|c|c|c|c|c|}
\hline \multicolumn{2}{|c|}{ Morphology } & \multirow{2}{*}{$\begin{array}{l}\text { Procedure } \\
\text { Single housing }\end{array}$} & \multirow{2}{*}{$\begin{array}{l}\text { Male vs female } \\
M>F\end{array}$} & \multirow{2}{*}{$\begin{array}{l}\text { Study } \\
\text { Juraska et al. [76] }\end{array}$} \\
\hline DG & Dendritic intersections of granule neurons in Long-Evans rats. & & & \\
\hline & Size of dendritic trees of granule neurons in Long-Evans rats & Enriched environment & $\mathrm{F}>\mathrm{M}$ & \\
\hline \multirow[t]{2}{*}{ CA3 } & $\begin{array}{l}\text { The number, length and size of mossy fiber increases in castrated male } \\
\text { Sprague-Dawley rats. Ovariectomy decreases dendritic spine density but } \\
\text { no effect on other parameters. (sexes not directly compared) }\end{array}$ & Gonadectomy & $\begin{array}{l}M<\text { mossy } \\
\text { fibers } \\
F<\text { spines }\end{array}$ & Mendell et al. [70] \\
\hline & $\begin{array}{l}\text { Apical dendritic complexity decreases in male Sprague-Dawley rats, } \\
\text { whereas basal dendritic complexity decreases in female Sprague-Dawley } \\
\text { rats. }\end{array}$ & Chronic stress & $\begin{array}{l}\mathrm{M}<\text { apical } \\
\mathrm{F}<\text { basal }\end{array}$ & Galea et al. [73] \\
\hline \multirow[t]{10}{*}{ CA1 } & $\begin{array}{l}\text { Apical dendritic spine density increases in male Sprague-Dawley rats but } \\
\text { decreases in females, dependent on estrous cycle phase. }\end{array}$ & Acute stress & $\begin{array}{l}\mathrm{M}> \\
\mathrm{F}<\end{array}$ & Shors et al. [75] \\
\hline & $\begin{array}{l}\text { Cell proliferation decreased in male, but not female Sprague-Dawley } \\
\text { rats. }\end{array}$ & Acute stress & $\begin{array}{l}\mathrm{M}< \\
\mathrm{F}=\end{array}$ & $\begin{array}{l}\text { Falconer and Galea } \\
{[110]}\end{array}$ \\
\hline & $\begin{array}{l}\text { The number of proliferating stem cells decreases in male, but not female } \\
\text { Wistar rats. }\end{array}$ & Repeated Stress & $\begin{array}{l}\mathrm{M}< \\
\mathrm{F}=\end{array}$ & $\begin{array}{l}\text { Tzeng et al [114]; } \\
\text { Hillerer et al. [118] }\end{array}$ \\
\hline & $\begin{array}{l}\text { After a stress incubation period, neurogenesis was reduced in females, } \\
\text { but not males. }\end{array}$ & & $\begin{array}{l}\mathrm{F}< \\
\mathrm{M}=\end{array}$ & Hillerer et al. [118] \\
\hline & $\begin{array}{l}\text { Maternal postpartum corticosterone (preweaning) decreases } \\
\text { neurogenesis in adult female offspring but not in male offspring } \\
\text { (Sprague-Dawley rats). }\end{array}$ & Corticosterone & $M>F$ & $\begin{array}{l}\text { Gobinath et al. [125, } \\
\text { 128] }\end{array}$ \\
\hline & $\begin{array}{l}\text { Early life stress causes by alterations in bedding or maternal deprivation, } \\
\text { reduces neurogenesis in adult male but not adult female mice or rats. }\end{array}$ & Chronic stress & $M<F$ & Naninck et al. [123] \\
\hline & $\begin{array}{l}\text { Stress during adolescence (restraint stress) reduces neurogenesis in } \\
\text { adult female, but increases neurogenesis in male rats. }\end{array}$ & Chronic stress & $M>F$ (Stress) & Barha et al. [127] \\
\hline & New neuron survival increases males but not females. & MWM & $M>F$ (Learning) & Chow et al. [129] \\
\hline & $\begin{array}{l}\text { Survival of new neurons increases in female, but not male, rats in the } \\
\text { ventral dentate gyrus. }\end{array}$ & $\begin{array}{l}\text { Trace eyeblink } \\
\text { conditioning }\end{array}$ & M > F (Basal) & Dalla et al. [117] \\
\hline & $\begin{array}{l}\text { Male place-strategy learners show greater adult neurogenesis than } \\
\text { female rats (dorsal). }\end{array}$ & RAM & $M>F$ (Learning) & Yagi et al. [109] \\
\hline
\end{tabular}

$D G$ dentate gyrus, MWM Morris water maze, RAM radial arm maze

of estrous cycle or season [64, 107, 111]. Galea and McEwen [107] showed that female wild meadow voles have greater cell proliferation in the dentate gyrus only during the non-breeding season compared to males. Furthermore, Tanapat et al. [64] showed that female Sprague Dawley rats during proestrus have greater cell proliferation compared to non-proestrous females and males. However, some studies have failed to find sex or estrous differences in cell proliferation in mice $[112,113]$, but others show the estrous cycle effect in mice [114]. In contrast to cell proliferation, most studies indicate that there are no significant sex differences in the survival of new neurons in rats, mice, or voles $[64,111,112,115,116]$ though Dalla et al. [117] found sex differences favouring male rats. Some studies do show sex differences, favouring males, in immature neurons in adulthood [118]. Sex hormones such as androgens and estrogens are potent modulators of adult neurogenesis in the hippocampus but a lengthy discussion of these effects is beyond the scope of this review. Briefly, estrogens modulate neurogenesis in females but to a lesser extent in males [116], whereas androgens modulate neurogenesis in males $[119,120]$ but it is not known if they modulate neurogenesis in females (for a review see [121]).

Sex differences in adult neurogenesis after exposure to stress Stress acts on adult neurogenesis in a sex-dependent manner $[110,118]$. For example, acute predator odor decreases cell proliferation in male, but not female rats [110] and this was not dependent on levels of testicular hormones in adult males [122] or ovarian hormone levels in adult females [110]. Similarly, repeated restraint stress reduced the number of proliferating stem cells in adult males, but not females [118]. However, 9 days after 12 days of restraint stress, neurogenesis was reduced in adult females, but not adult males [118], suggesting that the duration of time after stress exposure had more impact in females compared to males. Other studies find that both males and females show reduced neurogenesis to stress (footshock, water restraint) and these discrepancies are likely dependent on the nature of the stressor [114]. Together, these studies indicate the nature, duration and timing of the stressor as well as what aspect of neurogenesis is measured (proliferation, immature neurons, mature neurons) will affect the expression of sex differences on neurogenesis in the dentate gyrus.

Sex differences in adult neurogenesis after stress are dependent on the nature of the stressor but also when during the lifespan stress is given, with males more affected by short-term preweaning stress and females more affected by stress during puberty on adult neurogenesis. Early life stress, caused by alterations in bedding or maternal deprivation (postnatal day 2-9), reduces neurogenesis in adult male but not adult female mice [123]. However, maternal postpartum corticosterone across the entire postpartum (preweaning to weaning) decreases neurogenesis in adult female offspring but not in adult male offspring [124, 125]. In addition, $24 \mathrm{~h}$ of maternal deprivation on postnatal day 3 reduced DCX-expressing cells in females, but increased DCX-expression in males on postnatal day 21 [126], but it is not clear whether this difference would be seen in adulthood. Stress during adolescence (restraint stress) reduces neurogenesis in adult female, but increases neurogenesis male rats [127]. It is clear that stress can reveal sex differences in neurogenesis that depend on the timing of exposure to stress and the nature of the stressor, and for a comprehensive review on sex differences after 
a
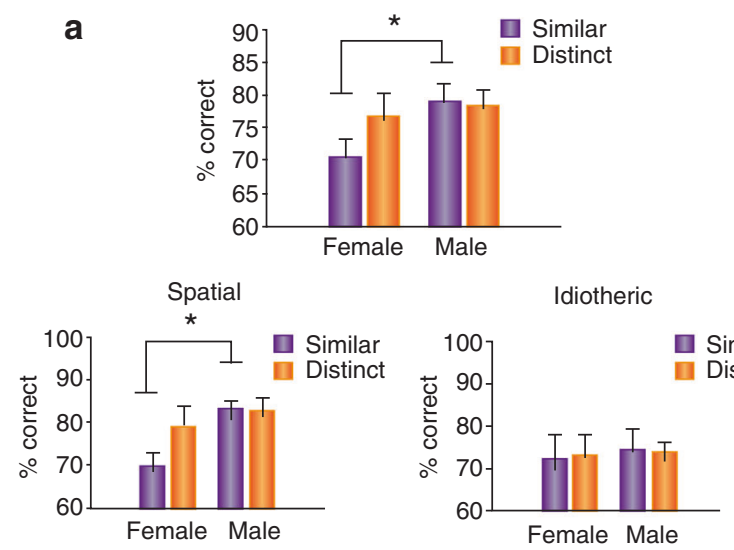

b

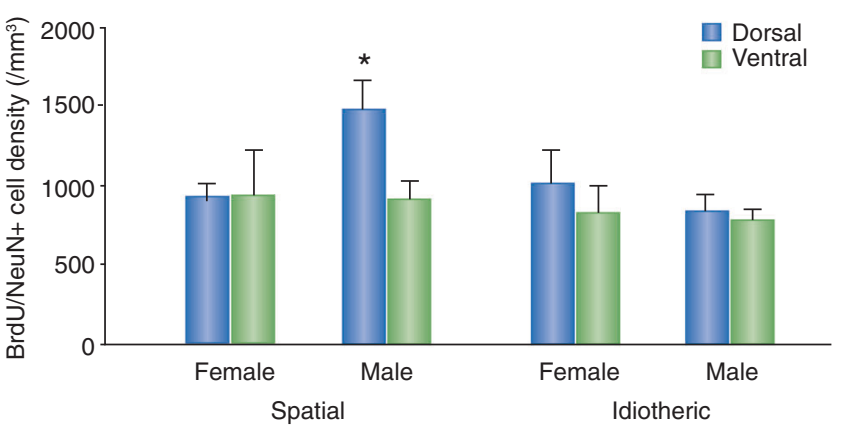

C

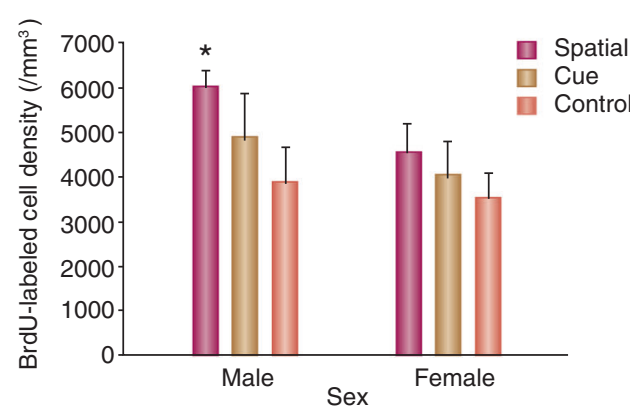

Fig. 2 Neurogenesis is modulated by learning differently based on sex. a Male rats separate similar patterns (adjacent arms) more efficiently than females. Male spatial strategy users had more correct responses on similar (adjacent) arms than female spatial strategy users. There were no sex differences in performance among idiothetic (response) strategy users [109]. b Male strategy users have more new neurons (BrdU/ NeuN cells) in the dorsal dentate gyrus compared to all other groups [109]. c Males that underwent spatial training (hidden platform in the Morris Water Maze) have more BrdU-labelled cells in the dentate gyrus compared to female rats that underwent hidden platform training (spatial), visible platform training (Cue), or cage controls (control) [129]. Figures are modified and reprinted with permission from Chow et al. [129] and Yagi et al. [109]. GCL granule cell layer

stress on neurogenesis the reader is directed to other reviews $[121,128]$.

Sex differences in adult neurogenesis after learning Adult neurogenesis is modulated by learning differently based on sex (Fig. 2), the direction of which is modified by sex differences in task performance [109, 117, 129]. Chow et al. [129] found that male rats outperformed female rats in acquiring the spatial version of the Morris water maze, which resulted in an enhancement of new neuron survival in the dentate gyrus of males but not females. Conversely, Dalla et al. [117] showed that diestrous female rats outperformed male rats in the trace eyeblink conditioning, which resulted in learning-enhanced survival of new neurons in female, but not male, rats in the ventral dentate gyrus. Yagi et al. [109] demonstrated through that males showed better performance in separating similar patterns and greater adult neurogenesis in the dorsal dentate gyrus than females. These results do not mean to suggest that females do not use the new neurons they create after learning as correlations are seen in the activity of new neurons in relation to performance in females but not in males [129]. Interestingly, male place learners with poor learning ability are more likely to show enhanced neurogenesis in response to spatial training compared to better learners [130]. Collectively, these findings indicate that task difficulty may be differently related to the neurogenic response by sex and/or that sex differences in the functional incorporation and integration of new neurons into the existing circuitry may be differently related to the degree of contribution of the hippocampus for learning.

\section{SEX DIFFERENCES IN HIPPOCAMPUS-DEPENDENT COGNITION} Sex differences in learning strategy

Previous studies in both humans [131-133] and rodents [134136] demonstrate that males and females differentially rely on two different learning strategies during spatial navigation tasks (Fig. 3). Place strategy engages the hippocampus, while response or cue strategy engages the striatum [137-139]. Men are more likely to use geometric cues and women are more likely to use landmark cues to reach a destination [140, 141]. In rodents, female rats preferentially use response strategies when ovarian hormones are low, while male rats preferentially use the place strategy to solve the same tasks [135, 141-143]. Studies have found that strategy choice varied in part by testosterone levels in male rats and ovarian hormones in female rats. Removal of testicular hormones by castration slightly reduced the preference for a place learning strategy [136] and low testosterone increased the use of a response strategy while high testosterone led to a preference for a place strategy in dual-solution water maze [144]. In contrast, female rats relied more on landmark cues during non-proestrous phases (lower levels of estradiol), and a place strategy during the proestrous phase (higher estradiol levels; [145]). This is consistent with other studies showing that higher levels of estradiol are associated with a place strategy and lower levels of estradiol with response strategies in female rats $[63,134,146,147]$. These sex differences in the preference of the two learning strategies suggest that males and females may rely on different brain regions during spatial training, and may contribute to sex differences in performance during spatial navigation. 
a

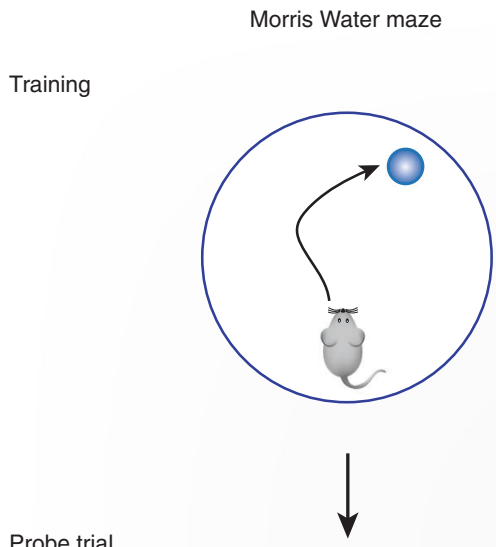

b
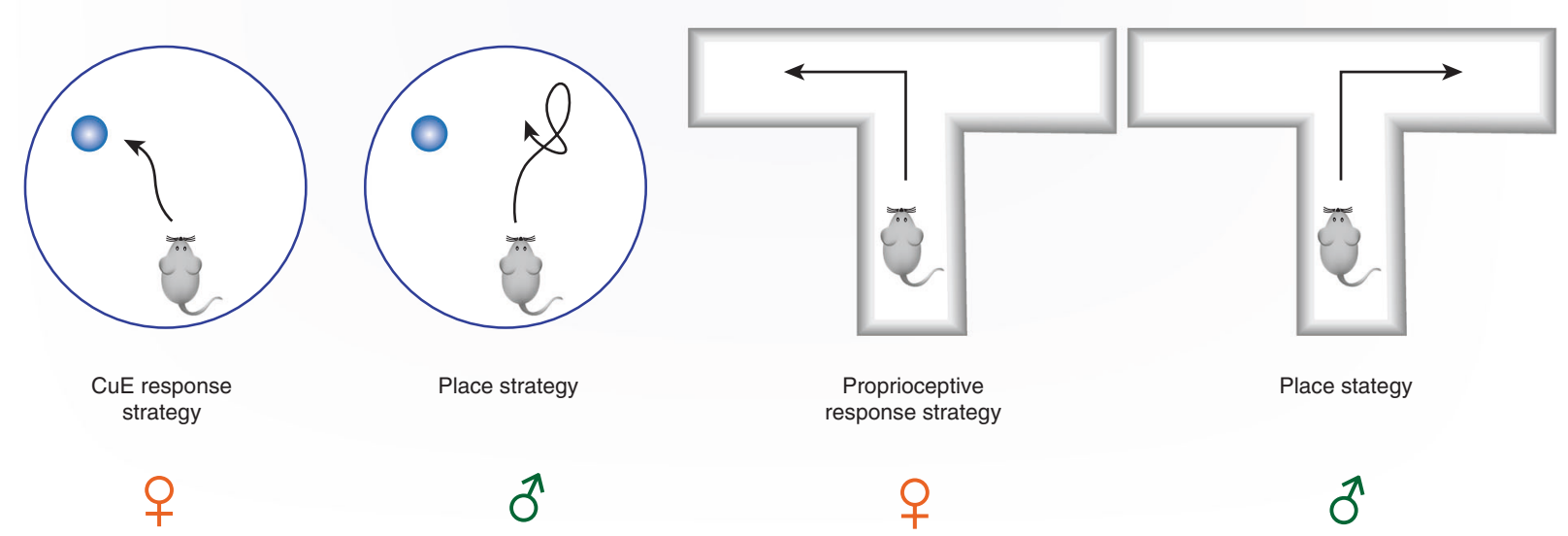

Fig. 3 Schematic illustrations for sex differences in spatial learning strategies in the (a) Morris Water Maze and (b) Dual T-Maze Task. Males are more likely to use geometric cues (place strategy) and females are more likely to use landmark cues (cue response strategy) or proprioceptive cues (proprioceptive response strategy) to reach a destination [135, 140-143]

Sex differences in spatial learning and memory

Meta-analyses indicate that males outperform females on tasks of spatial navigation and working memory, in both human and rodent studies [148-150]. For instance, Galea and Kimura [141] demonstrated that men made fewer errors to recall a learned route on a map, but intriguingly women remembered more landmarks along the route than men, indicating differential attention to cues in men versus women while route learning. In agreement with human studies, male rodents outperform female rodents in a variety of spatial navigation and working memory tasks [150]. However, a number of studies have failed to demonstrate sex differences in spatial navigation tasks. This inconsistency may be due to types of spatial tasks, strategy use, stress exposure, cues that can be used to solve the task, and/or hormone levels. As described in the previous section ('Sex differences in learning strategy'), males and females have different tendencies to rely on the hippocampus-dependent place strategy or the striatum-dependent response strategy. Indeed, a sex difference favouring males exists in the standard reference memory version of the Morris water maze task; but there is no sex difference observed during a cue competition task in which subjects can use both the place and response strategy to solve the task [147]. Furthermore, the environmental cues within the task can dictate whether sex differences in performance are seen. Men perform more accurately to find a platform location than women when more geometric spatial cues exist in the virtual water maze, whereas there is no sex difference when more landmark cues exist [151]. These findings imply that males and females use different strategies, or exhibit differential cue use, to solve the same maze.
Indeed, males attend to geometric cues while females attend to landmark and visual cues to solve spatial tasks in both humans and rodents [141, 142]. Thus, it is important to ensure that cues are considered when using both males and females in spatial tasks, as these may significantly influence whether sex differences will be seen.

Reviews in neuroscience suggest that studies are underpowered to detect sex differences [152]. However, this review fails to appreciate that conditions of testing are important in the outcome of sex differences on learning such as cue availability affecting strategy use, housing, hormone levels, and temperature of the water, that all contribute to whether sex differences in spatial acquisition are seen or not. Indeed, Button et al. [152] suggests that sample sizes of 68-134 are required to demonstrate a sex difference. We suggest that the sample size needed to detect a sex difference in spatial performance is much lower if attention is paid to parameters such as cue choice. The heterogeneity in findings on sex differences in spatial ability, are more likely due to variability in protocols and experimental conditions, affecting effective strategy use rather than whether a true sex difference in spatial ability exists. Variability in cognitive testing has lead more than one researcher to suggest the use of standardized protocols/testing [153] and new efforts are underway to share and compare data via platforms such as http:// mousebytes.ca/home to improve our understanding of biological variations influence learning.

While there are fewer studies, studies examining the ability to perform pattern separation indicate that males perform more accurately in challenging spatial pattern separation tasks 

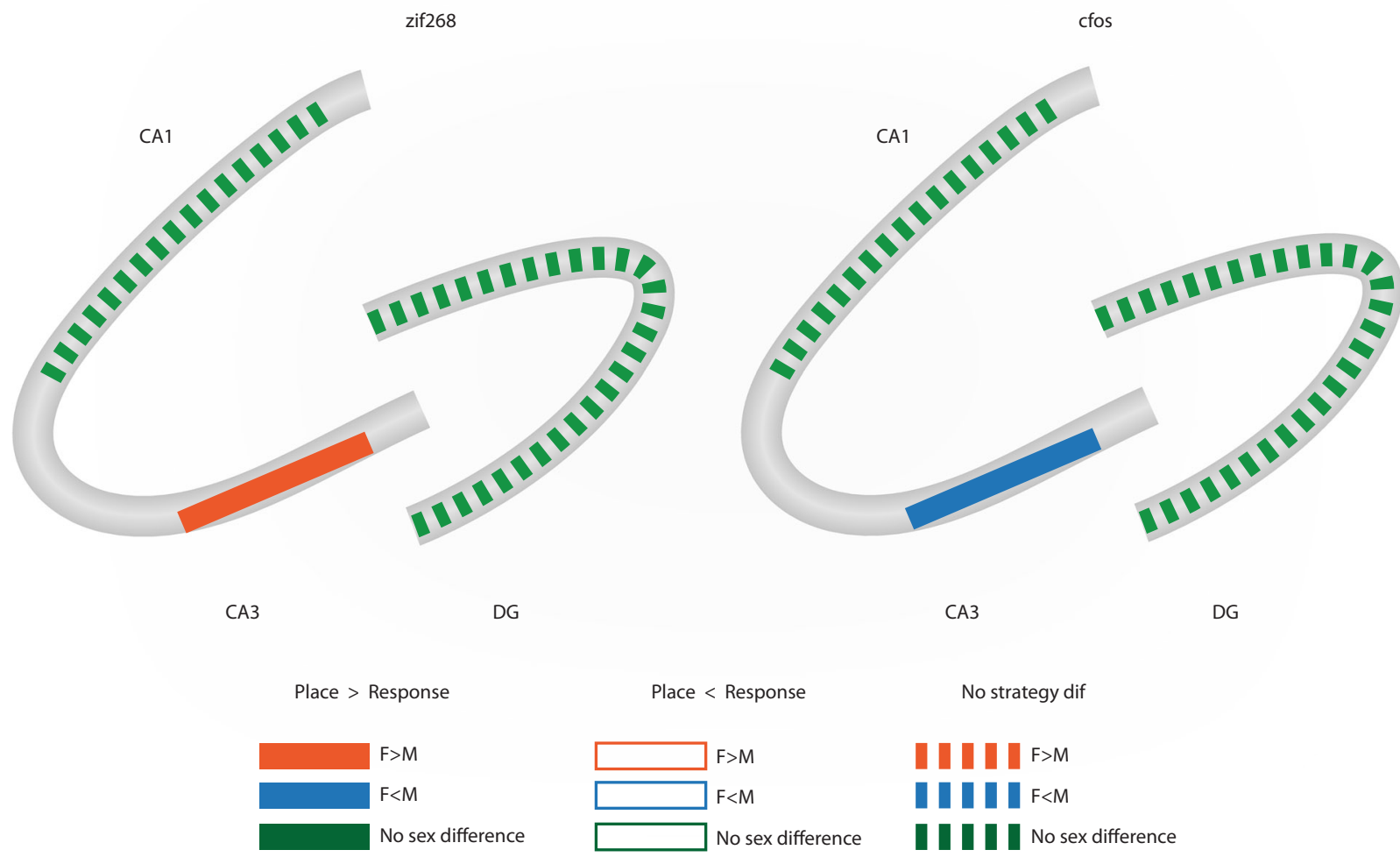

Fig. 4 Summary for sex and strategy differences in different (zif268, cfos) immediate early gene (IEG) expression in the hippocampus 90 min after memory retrieval in different hippocampus-dependent tasks (data compiled from [109, 147]). Female place strategy users have greater zif268 expression in the CA3 compared to female response strategy users and males, while male place strategy users have greater cfos expression in the CA3 compared to all other groups after a cue competition task [147]

compared to females [109]. For example, comparing two different studies where sex was not compared statistically, male mice were able to distinguish two adjacent arms in the radial 8-arm maze [92], while a different research group reported that females failed to distinguish the two adjacent arms in this same task [94]. However, both sexes performed equally well in distinguishing between distant arms in that task [92, 94]. Although these data are only suggestive, these studies were conducted using mice with different genetic backgrounds, and thus conclusive evidence for sex differences in the ability for pattern separation cannot be established using those two studies. Yagi et al. [109] found sex differences in pattern separation performance (see Fig. 2). In separate analyses of arms, we showed that males were better at pattern separation of similar, but not distinct, patterns. However, an a priori analysis revealed that male place strategy users outperformed female place strategy users when separating similar patterns during a pattern separation task, whereas there were no significant sex differences among response strategy users [109]. Although not originally reported the effect size (Cohen's d) for the sex difference favouring males in performance on similar arms was 1.73 , and 0.6 for distinct arms. This study also demonstrated that male place strategy users had greater number of adult born neurons in the dorsal dentate gyrus than all other groups. Furthermore, the number of new neurons in the ventral dentate gyrus was more strongly associated with the ability to distinguish two adjacent arms (similar patterns) in female place strategy users, although a trend existed in males and caution should be noted as the sample size was small. These results suggest that new neurons in the dorsal hippocampus are more responsive to enhancing effect of spatial learning on survival of new neurons in males.
Whereas, the relationship of neurogenesis in the ventral hippocampus in females with performance suggests that female performance is more sensitive to stress and/or that different connectivity patterns may exist between males and females in the dorsal versus ventral hippocampus, an effect detected in humans [40].

Sex differences in spatial learning and memory: relationship to stress

The idea that female performance may be more sensitive to stress, may explain some sex differences seen in the Morris water maze. When rats were pre-exposed to the environment these studies failed to demonstrate the sex difference in spatial performance $[150,154]$. Pre-exposure to the water maze reduces the stress levels and circulating levels of stress hormones during the testing sessions and it is possible that females perform better under a less stressful environment $[155,156]$. However, studies in meadow voles that used a pre-exposure baseline session consistently showed sex differences favouring males (for review see [157]). It is important to understand that the sex differences in learning also depend on factors such as maternal care experience [158] and gonadal hormone concentrations in males and females (for review see: [91]). While beyond the scope of this review, estradiol levels in females drive spatial acquisition, and as such, lower estradiol in females is associated with better performance in both rodents and in women ([159, 160]; see [91] for review). Given that stress increases estradiol levels in females [161], it may be that this initially exposure to stress serves to increase estradiol levels, pushing the trajectory to poorer performance in females relative to males. 
Studies examining learning after stressful experiences show sex differences in performance $[162,163]$. Repeated restraint stress (21 days) reduces dendritic complexity in the apical or basal dendrites of CA3 pyramidal neurons of males and females, respectively [73]. However, this same stress regime results in opposing effects on spatial acquisition with impairments in males but improvements in females although the sexes were not directly compared in one study for learning outcomes (reviewed in [164]). Thus, seemingly small differences (apical vs basal) to the architecture of dendrites can lead to opposing effects on spatial memory between the sexes. This association of a reduction in branching leading to an improvement in learning outcomes, or an increase in spines related to a time of impairments in learning outcomes, is a pattern that is often seen in females. It is possible that the signal to noise ratio is different between males and females, and given the greater excitability of the hippocampus in females, female neurons may require pruning of hippocampal neurons to achieve better learning outcomes. This opposing pattern of stress on outcome in males versus females is also seen in studies examining transcriptome after stress, with female mice showing an greater increase compared to males in DNA methyltransferase 3a gene expression, which is an important regulator for synaptic plasticity, in the nucleus accumbens (NAc) after subchronic variable stress [165]. Unfortunately, there are very few studies on the 'sexome' done to date [166]. The few studies completed do suggest a number of differences between males and females in gene expression in the hippocampus with aging and disease [167-170] that may be related to sex differences in cognition. For instance, the number of upregulated genes with aging in the hippocampus of women is two times greater than that of men [169]. These up-regulated genes include genes regulating cell apoptosis, cytokine activity and cell metabolism, which directly or indirectly interact with cell aging and cell death. Studies examining transcriptomic analyses in the hippocampus indicate that there are sex differences [171, 172]. For example, hippocampal mRNA expression for heat-shock proteins, that are proposed to regulate dendritic spines, is greater in adult male compared to adult female mice [171]. More studies directly comparing males and females are essential for further understanding of underlying mechanisms of sex differences in hippocampal function. These transcriptome results give us important clues how sex may interact with hippocampal function, and more research is needed to elucidate the molecular mechanisms of sex differences. As stress modulates learning and memory, and plasticity-related gene expression in the hippocampus differently between sexes, researchers should carefully control experimental environment of research subjects. Furthermore, future studies should include detailed information about experimental procedures especially factors that potentially influence behavioral outcomes such as length of handling, housing conditions, and water temperature of water maze.

Sex differences in immediate early gene (IEG) expression after memory retrieval

Cellular activity in response to spatial memory can be examined by quantifying expression of IEG proteins such as zif268, cfos and Arc, which are rapidly induced after learning and regulate learning-related neural plasticity $[173,174]$. Although LTP is not required for $c$-fos induction $[175,176]$, the IEG zif268 encodes the zinc finger transcription factors zif268/Egr1 (early growth response protein1) which plays a critical role in the maintenance of LTP in the hippocampus and in the consolidation of long-term memory $[174,177,178]$. Only a few studies have examined sex differences in response to spatial and non-spatial learning on IEGs (see Fig. 4). Yagi et al. [147] found that in the CA3 male place learners showed greater cfos expression, while female place learners showed greater zif268 expression. Intriguingly, there were sex by strategy use differences in activation with female place strategy users showing greater zif268 expression but less cfos expression in the CA3 compared to cue strategy users. This same relationship in the CA3 region was seen after pattern separation with greater zif268 expression in females, but more cfos expression in males [109]. These sex differences in the expression of IEGs were only seen in the dorsal hippocampus, which is intriguing as the dorsal area is more tightly linked to spatial reference memory [179]. Furthermore, none of these same sex differences in IEG expression were present in the CA1 or DG. These results suggest that greater number of zif268-expressing CA3 pyramidal neurons in response to memory retrieval in female compared to male rats, may help recruit LTP, as zif268 is strongly associated with LTP. Intriguingly, changes in cfos expression after spatial memory retrieval are seen across the estrous cycle with rats in proestrous having greater cfos expression in the dentate gyrus than rats not in proestrus [147]. While a few studies have examined sex differences in the expression of cfos and zif268, no studies have been conducted using Arc to determine underlying mechanisms of sex differences in spatial learning ability, or Arc expression of newly produced neural dendrites in the dentate gyrus, which is a clear gap in the literature.

One study has reported sex differences in activation of adultborn cells in the dentate gyrus relating to performance [129]. In that study, zif268 protein expression was examined after memory retrieval in the Morris water maze 20 days after cell birth. Spatially-trained rats showed greater activation than cuetrained rats with no overall sex differences in expression of activated new neurons. However, greater activation of new neurons was strongly associated with better performance in female rats but not in male rats, suggesting the pattern of the associations are different between males and females, although the correlations were not statistically compared in the original paper, in doing so now these correlations are statistically different $(z=-2.05, p=0.04)$. This sex difference may be due to sex differences in excitability of 20 days old neurons, in the timing of expression of zif268, and/or the maturation rate of new neurons and further research is encouraged in these areas.

Researchers should also be aware that production of these IEG proteins after learning has different time courses dependent on the IEG $[180,181]$. For instance, zif268 protein expression reaches peak levels $60 \mathrm{~min}$ after learning [180], whereas, albeit to different stimuli (pentylenetetrazol-induced seizures), cfos protein expression reaches its peak at 60-120 min after the seizure [181]. These differences in induction time courses must be carefully considered when comparing the different IEG expression after learning. We suggest that these sex differences in IEG expression seen after learning may be due not only to different IEGs being recruited during different tasks, but also different regions may show different IEG expression responses, and there may be different timing in IEG expression between the sexes that contribute to these differences.

Sex differences in contextual fear conditioning

The hippocampus is also important for contextual fear learning and memory. Women show a greater prevalence of posttraumatic stress disorder (PTSD) with more generalization of fear memories compared to men [182, 183]. Furthermore, women show greater pain sensitivity and anxiety within the context of previously experienced painful event [184]. Female rats demonstrated greater generalization of fear related contextual memory and prolonged fear memory compared to male rats [185]. Lynch et al. [186] examined fear memory generalization using two different contexts: one with electric foot shock and the other without foot shock. They examined passive avoidance of fear (foot shock) related context $1 \mathrm{~d}, 3 \mathrm{~d}, 5 \mathrm{~d}$, and $7 \mathrm{~d}$ after conditioning. Females gradually showed increased fear related response in the neutral context while male rats did not show such an increase and even at $7 \mathrm{~d}$ after conditioning, male rats showed the ability to discriminate 
between the two contexts. These studies and others [187] demonstrate that females may have more fear generalization than males which may contribute to the findings that women are more susceptible to fear generalization disorders such as PTSD.

Females show less extinction to contextual fear conditioning than males [188, 189], but males show stronger retention and more freezing to the conditioned stimulus especially after preexposure $[185,187,190]$. Males are typically found to have stronger or greater long-term retention of contextual fear conditioning [187], which coincided with increased levels of phosphorylated ERK in the ventral hippocampus of males but not females. Using a context pre-exposure paradigm that relies on the integrity of the dentate gyrus, gonadetomized males and intact males were found to have stronger contextual fear conditioning than females [185, 190]. A caveat with respect to these findings is that researchers have traditionally used freezing as an index of fear memory. However, females show more active patterns of fear expression termed 'darting' [191], and thus care must be taken in fear conditioning paradigms to assess the appropriate behaviors in males and females.

These sex differences in conditioned fear responses may be related to sex differences in activation with greater neural activation (cFos) in the basal amygdala of females and in the dorsal hippocampus of males [185, 192]. Keiser et al. [185] suggest this may have to do with the competition between the amygdala and hippocampus but it is also possible that different IEGs or different time points may find a different pattern of activation after fear conditioning. Sex differences in neural patterns may be seen even when there are no sex differences in conditioning strength, as work from the Shansky laboratory as noted sex differences in the prefrontal cortex to amygdala circuits, even when there were no overt sex differences in behavior [193]. It is clear that care must be taken when studying sex differences in fear conditioning, including type of conditioning (cue, contextual), behavior measured (freezing, darting), and pre-exposure to the context.

\section{FUTURE DIRECTIONS AND CLINICAL IMPLICATIONS}

Studying sex differences in hippocampal cognition and neural plasticity, while potentially controversial, is important, as it will aid in elucidating the underlying mechanisms of sex differences in prevalence or manifestation of disorders that disrupt hippocampal integrity and result in cognitive disruption. Furthermore, studying sex differences in cognitive outcome may be important in understanding precision medicine. For example, studies indicate that exercise can offset cognitive decline with the type of exercise related to differential efficacy in men versus women [194] and indeed physical activity can increase hippocampal subregions differently in women versus men [195]. It is vital to understand what exercise regimen (or any type of treatment) may be more beneficial to men versus women to combat disease and agingrelated cognitive decline [194]. A number of studies demonstrate sex differences in associations between hippocampal adult neurogenesis and cognition. These findings imply that sexspecific approaches for clinical treatment to increase the treatment efficacy for cognitive decline or disruption may be needed. We emphasize the importance of studying sex differences in measures of hippocampal function. We also caution the community as while the use of both sexes has been mandated in NIH-sponsored clinical trials since 1993 (NIH, 1993), the appropriate sample size, and analyses have not always been reported in the literature. Furthermore, this sex-inclusion mandate does not extend to clinical trials that are not sponsored by $\mathrm{NIH}$, and these trials form the majority of clinical trials listed on clinicaltrials.gov (over 85\%). Researchers are encouraged to include males and females in their experiments, and to analyze their data stratified by sex adhering to issues on statistical interpretations of an interaction effect [196]. Furthermore, it is equally important to consider age and hormone status in their studies to gain a clearer picture of how sex differences may be contributing to measures of interest. These efforts will provide the academic and clinical communities with invaluable information that we hope will lead to more efficient clinical treatment for both men and women.

\section{ACKNOWLEDGEMENTS}

Research described from LAMG laboratory was funded by operating grants from Natural Sciences and Engineering Council of Canada (NSERC) (203596-13) and Canadian Institutes for Health Research (CIHR) MOP102568. SY gratefully acknowledges support from the Killam Doctoral Scholarship through the University of British Columbia.

\section{ADDITIONAL INFORMATION}

Competing interests: The authors declare no competing interests.

Publisher's note: Springer Nature remains neutral with regard to jurisdictional claims in published maps and institutional affiliations.

\section{REFERENCES}

1. McPherson S, Back C, Buckwalter JG, Cummings JL. Gender-related cognitive deficits in Alzheimer's disease. Int Psychogeriatr. 1999;11:117-22.

2. Brookmeyer R, Gray S, Kawas C. Projections of Alzheimer's disease in the United States and the public health impact of delaying disease onset. Am J Public Health. 1998;88:1337-42.

3. Gutiérrez-Lobos $K$, Scherer $M$, Anderer $P$, Katschnig $H$. The influence of age on the female/male ratio of treated incidence rates in depression. BMC Psychiatry. 2002;2:3.

4. Irvine K, Laws KR, Gale TM, Kondel TK. Greater cognitive deterioration in women than men with Alzheimer's disease: a meta analysis. J Clin Exp Neuropsychol. 2012;34:989-98.

5. Hy LX, Keller DM. Prevalence of AD among whites: a summary by levels of severity. Neurology. 2000;55:198-204.

6. Leung A, Chue P. Sex differences in schizophrenia, a review of the literature. Acta Psychiatr Scand Suppl. 2000;401:3-38.

7. Mossaheb N, Kaufmann RM, Schlögelhofer M, Aninilkumparambil T, Himmelbauer C, Gold A, et al. The impact of sex differences on odor identification and facial affect recognition in patients with schizophrenia spectrum disorders. Front Psychiatry. 2018;9:1-8.

8. Nicoletti A, Vasta R, Mostile G, Nicoletti G, Arabia G, lliceto G, et al. Gender effect on non-motor symptoms in Parkinson's disease: are men more at risk? Park Relat Disord. 2017;35:69-74.

9. Szewczyk-Krolikowski K, Tomlinson P, Nithi K, Wade-Martins R, Talbot K, BenShlomo $Y$, et al. The influence of age and gender on motor and non-motor features of early Parkinson's disease: initial findings from the Oxford Parkinson Disease Center (OPDC) discovery cohort. Park Relat Disord. 2014;20:99-105.

10. Cereda E, Cilia R, Klersy C, Siri C, Pozzi B, Reali E, et al. Dementia in Parkinson's disease: is male gender a risk factor? Park Relat Disord. 2016;26:67-72.

11. Han M, Huang XF, Chen DC, Xiu MH, Hui L, Liu H, et al. Gender differences in cognitive function of patients with chronic schizophrenia. Prog NeuroPsychopharmacol Biol Psychiatry. 2012;39:358-63.

12. De Vries GJ. Minireview: sex differences in adult and developing brains: compensation, compensation, compensation. Endocrinology. 2004;145:1063-8.

13. Becker JB, Koob GF. Sex Differences in Animal Models: Focus on Addiction. Pharmacol Rev. 2016;68:242-63.

14. Christie BR, Cameron HA. Neurogenesis in the adult hippocampus. Hippocampus. 2006;16:199-207.

15. Eriksson PS, Perfilieva E, Björk-Eriksson T, Alborn aM, Nordborg C, Peterson DA et al. Neurogenesis in the adult human hippocampus. Nat Med. 1998;4: 1313-7.

16. Neves G, Cooke SF, Bliss TVP. Synaptic plasticity, memory and the hippocampus: a neural network approach to causality. Nat Rev Neurosci. 2008;9:65-75.

17. McEwen BS. Redefining neuroendocrinology: epigenetics of brain-body communication over the life course. Front Neuroendocrinol. 2018;49:8-30.

18. Whitlock JR, Heynen AJ, Shuler MG, Bear MF. Learning induces long-term potentiation in the hippocampus. Science 2006;313:1093-7.

19. Artola A, Frijtag JCVon, Fermont PCJ, Gispen WH, Schrama LH, Kamal A, et al. Long-lasting modulation of the induction of LTD and LTP in rat hippocampal 
CA1 by behavioural stress and environmental enrichment. Eur J Neurosci. 2006;23:261-72.

20. Hunsaker MR, Kesner RP. The operation of pattern separation and pattern completion processes associated with different attributes or domains of memory. Neurosci Biobehav Rev. 2013;37:36-58.

21. Zhang JQ, Cai WQ, Zhou DS, Su BY. Distribution and differences of estrogen receptor beta immunoreactivity in the brain of adult male and female rats. Brain Res. 2002;935:73-80.

22. Feng $Y$, Weijdegård B, Wang T, Egecioglu E, Fernandez-Rodriguez J, Huhtaniemi I, et al. Spatiotemporal expression of androgen receptors in the female rat brain during the oestrous cycle and the impact of exogenous androgen administration: a comparison with gonadally intact males. Mol Cell Endocrinol. 2010;321:161-74.

23. Mitterling KL, Spencer JL, Dziedzic N, Shenoy S, McCarthy K, Waters EM, et al. Cellular and subcellular localization of estrogen and progestin receptor immunoreactivities in the mouse hippocampus. J Comp Neurol. 2010;518:2729-43.

24. Mogi K, Takanashi H, Nagasawa M, Kikusui T. Sex differences in spatiotemporal expression of $A R, E R a$, and $E R \beta$ mRNA in the perinatal mouse brain. Neurosci Lett. 2015;584:88-92.

25. McEwen BS, Weiss JM, Leslie SS. Selective retention of corticosterone by limbic structures in rat brain. Nature. 1968;220:911-2.

26. Mocuilewsky M, Raynaud JP. Evidence for a specific mineralocorticoid receptor pituitary and brain. J Steroid Biochem. 1980;12:309-14

27. Aronsson M, Fuxe K, Dong Y, Agnati LF, Okret S. Localization of glucocorticoid receptor mRNA in the male rat brain by in situ Hybridization. Proc Natl Acad Sci USA. 1988;85:9331-5.

28. Wang Q, Heerikhuize JVan, Aronica E, Kawata M, Seress L, Joels M, et al. Glucocorticoid receptor protein expression in human hippocampus; stability with age. Neurobiol Aging. 2013;34:1662-73.

29. Owen D, Matthews SG. Glucocorticoids and sex-dependent development of brain glucocorticoid and mineralocorticoid receptors. Endocrinology. 2003;144:2775-84.

30. Ruigrok ANV, Salimi-Khorshidi G, Lai M-C, Baron-Cohen S, Lombardo MV, Tait RJ, et al. A meta-analysis of sex differences in human brain structure. Neurosci Biobehav Rev. 2014;39:34-50.

31. Tan A, Ma W, Vira A, Marwha D, Eliot L. The human hippocampus is not sexuallydimorphic: meta-analysis of structural MRI volumes. Neuroimage. 2016;124:350-66. Meta-analysis showing that sex differences in the volume of the hippocampus are explained by total brain volume differences between the sexes

32. Tamnes CK, Bos MGN, van de Kamp FC, Peters S, Crone EA. Longitudinal development of hippocampal subregions from childhood to adulthood. Dev Cogn Neurosci. 2018;30:212-22.

33. Colle R, Segawa T, Chupin M, Tran Dong MN, Hardy P, Falissard B, et al. Early life adversity is associated with a smaller hippocampus in male but not female depressed in-patients: a case-control study. BMC Psychiatry. 2017;17:71.

34. Lisofsky N, Mårtensson J, Eckert A, Lindenberger U, Gallinat J, Kühn S. Hippocampal volume and functional connectivity changes during the female menstrual cycle. Neuroimage. 2015;118:154-62. This study demonstrate the dynamics of female hippocampal volume and functional connectivity, in which increase of estradiol leads to an increase of hippocampal volume

35. Hoekzema E, Barba-Müller E, Pozzobon C, Picado M, Lucco F, García-García D, et al. Pregnancy leads to long-lasting changes in human brain structure. Nat Neurosci. 2017;20:287-96. One of the first studies to show long-term changes to the brain, including the hippocampus, after pregnancy, and that these reductions in grey matter were associated with positive parenting outcomes, indicating that more is not always better

36. Wnuk A, Korol DL, Erickson KI. Estrogens, hormone therapy, and hippocampal volume in postmenopausal women. Maturitas. 2012;73:186-90.

37. Goto M, Abe O, Miyati T, Inano S, Hayashi N, Aoki S, et al. 3 Tesla MRI detects accelerated hippocampal volume reduction in postmenopausal women. J Magn Reson Imaging. 2011;33:48-53.

38. Everaerd D, Gerritsen L, Rijpkema M, Frodl T, Van Oostrom I, Franke B, et al. Sex modulates the interactive effect of the serotonin transporter gene polymorphism and childhood adversity on hippocampal volume. Neuropsychopharmacology. 2012;37:1848-55.

39. Lord C, Buss C, Lupien SJ, Pruessner JC. Hippocampal volumes are larger in postmenopausal women using estrogen therapy compared to past users, never users and men: A possible window of opportunity effect. Neurobiol Aging. 2008;29:95-101.

40. Persson J, Spreng RN, Turner G, Herlitz A, Morell A, Stening E, et al. Sex differences in volume and structural covariance of the anterior and posterior hippocampus. Neuroimage. 2014;99:215-25.
41. Sacher J, Neumann J, Okon-Singer H, Gotowiec S, Villringer A. Sexual dimorphism in the human brain: evidence from neuroimaging. Magn Reson Imaging. 2013;31:366-75.

42. Scheinost D, Finn ES, Tokoglu F, Shen X, Papademetris X, Hampson M, et al. Sex differences in normal age trajectories of functional brain networks. Hum Brain Mapp. 2015;36:1524-35.

43. Zhang C, Cahill ND, Arbabshirani MR, White T, Baum SA, Michael AM. Sex and Age Effects of Functional Connectivity in Early Adulthood. Brain Connect. 2016;6:700-13. This is the first study showing sex and age effects on the whole brain functional connectivity with resting-state functional MRI. This study demonstrated that men's and women's brains are differently organized compared to young adults and the functional organization changes differently between the sexes with age

44. Ingalhalikar M, Smith A, Parker D, Satterthwaite TD, Elliott MA, Ruparel K, et al. Sex differences in the structural connectome of the human brain. Proc Natl Acad Sci. 2014;111:823-8.

45. Joel D, Berman Z, Tavor I, Wexler N, Gaber O, Stein Y, et al. Sex beyond the genitalia: the human brain mosaic. Proc Natl Acad Sci. 2015;112:15468-73.

46. Filippi M, Valsasina P, Misci P, Falini A, Comi G, Rocca MA. The organization of intrinsic brain activity differs between genders: a resting-state fMRI study in a large cohort of young healthy subjects. Hum Brain Mapp. 2013;34:1330-43.

47. Gobinath AR, Choleris E, Galea LA. Sex, hormones, and genotype interact to influence psychiatric disease, treatment, and behavioral research. J Neurosci Res. 2017a;95:50-64.

48. Glezerman M. Yes, there is a female and a male brain: morphology versus functionality. Proc Natl Acad Sci. 2016;113:E1971-E1971.

49. Baxter LC, Saykin AJ, Flashman LA, Johnson SC, Guerin SJ, Babcock DR, et al. Sex differences in semantic language processing: a functional MRI study. Brain Lang. 2003;84:264-72.

50. Kansaku K, Yamaura A, Kitazawa S. Sex differences in lateralization revealed in the posterior language areas. Cereb Cortex. 2000;10:866-72.

51. Sneider JT, Sava S, Rogowska J, Yurgelun-Todd DA. A preliminary study of sex differences in brain activation during a spatial navigation task in healthy adults. Percept Mot Skills. 2011;113:461-80.

52. Grön G, Wunderlich AP, Spitzer M, Tomczak R, Riepe MW. Brain activation during human navigation:gender-different neural networks as substrate performance. Nat Neurosci. 2000:3:404-8.

53. Kolb B, Stewart J. Changes in the neonatal gonadal hormonal environment prevent behavioral sparing and alter cortical morphogenesis after early frontal cortex lesions in male and female rats. Behav Neurosci. 1995;109:285-94.

54. Padurariu M, Ciobica A, Mavroudis I, Fotiou D, Baloyannis S. Hippocampal neuronal loss in the $\mathrm{Ca} 1$ and $\mathrm{Ca} 3$ areas of Alzheimer'. S Dis Patients. 2012;24:152-8

55. Kerchner GA, Deutsch GK, Zeineh M, Dougherty RF, Saranathan M, Rutt BK. Hippocampal CA1 apical neuropil atrophy and memory performance in Alzheimer's disease. Neuroimage. 2012;63:194-202.

56. Sabuncu M, Desikan R. The dynamics of cortical and hippocampal atrophy in Alzheimer disease. Arch Neurol. 2011;68:1040-8.

57. Henneman WJP, Sluimer JD, Barnes J, Van Der Flier WM, Sluimer IC, Fox NC, et al. Hippocampal atrophy rates in Alzheimer disease: added value over whole brain volume measures. Neurology. 2009;72:999-1007.

58. Martínez-Pinilla E, Ordóñez C, Del Valle E, Navarro A, Tolivia J. Regional and gender study of neuronal density in brain during aging and in Alzheimer's disease. Front Aging Neurosci. 2016;8:213.

59. Koran MEl, Wagener M, Hohman TJ. Sex differences in the association between AD biomarkers and cognitive decline. Brain Imaging Behav. 2017;11:205-13.

60. Sohn D, Shpanskaya K, Lucas JE, Petrella JR, Saykin AJ, Tanzi RE, et al. Sex differences in cognitive decline in subjects with high likelihood of mild cognitive impairment due to Alzheimer's disease. Sci Rep. 2018;8:1-9.

61. Burke SL, Hu T, Fava NM, Li T, Rodriguez MJ, Schuldiner KL, et al. Sex differences in the development of mild cognitive impairment and probable Alzheimer's disease as predicted by hippocampal volume or white matter hyperintensities. J Women Aging. 2018;10:1-25.

62. Caldwell JZK, Berg JL, Cummings JL, Banks SJ, Alzheimer's Disease Neuroimaging Initiative. Moderating effects of sex on the impact of diagnosis and amyloid positivity on verbal memory and hippocampal volume. Alzheimers Res Ther. 2017;9:72.

63. Rummel J, Epp JR, Galea LAM. Estradiol does not influence strategy choice but place strategy choice is associated with increased cell proliferation in the hippocampus of female rats. Horm Behav. 2010;58:582-90.

64. Tanapat $P$, Hastings NB, Reeves AJ, Gould E. Estrogen stimulates a transient increase in the number of new neurons in the dentate gyrus of the adult female rat. J Neurosci. 1999;19:5792-801. 
65. Qiu LR, Germann J, Spring S, Alm C, Vousden DA, Palmert MR, et al. Hippocampal volumes differ across the mouse estrous cycle, can change within 24h, and associate with cognitive strategies. Neuroimage. 2013;83:593-8.

66. Warren SG, Humphreys AG, Juraska JM, Greenough WT. LTP varies across the estrous cycle: enhanced synaptic plasticity in proestrus rats. Brain Res. 1995;703:26-30.

67. Good M, Day M, Muir JL. Cyclical changes in endogenous levels of oestrogen modulate the induction of LTD and LTP in the hippocampal CA1 region. Eur J Neurosci. 1999;11:4476-80.

68. Woolley CS, Gould E, Frankfurt M, McEwen BS. Naturally occurring fluctuation in dendritic spine density on adult hippocampal pyramidal neurons. J Neurosci. 1990;10:4035-9.

69. Tada H, Koide M, Ara W, Shibata Y, Funabashi T, Suyama K, et al. Estrous cycledependent phasic changes in the stoichiometry of hippocampal synaptic AMPA receptors in rats. PLoS ONE. 2015;10:e0131359.

70. Mendell AL, Atwi S, Bailey CDC, McCloskey D, Scharfman HE, MacLusky NJ. Expansion of mossy fibers and CA3 apical dendritic length accompanies the fall in dendritic spine density after gonadectomy in male, but not female, rats. Brain Struct Funct. 2017;222:587-601.

71. Gould E, Woolley CS, Frankfurt M, McEwen BS. Gonadal steroids regulate dendritic spine density in hippocampal pyramidal cells in adulthood. J Neurosci. 1990b;10:1286-91. An early study indicating that phase of estrous cycle influence spine density in the CA1 region of the hippocampus

72. Juraska JM, Fitch JM, Washburne DL. The dendritic morphology of pyramidal neurons in the rat hippocampal CA3 area. II. Eff Gend Environ Brain Res. 1989;479:115-9.

73. Galea LA, McEwen B, Tanapat P, Deak T, Spencer R, Dhabhar F. Sex differences in dendritic atrophy of $C A 3$ pyramidal neurons in response to chronic restraint stress. Neuroscience. 1997;81:689-97.

74. Gould E, Westlind-Danielsson A, Frankfurt M, McEwen BS. Sex differences and thyroid hormone sensitivity of hippocampal pyramidal cells. J Neurosci. 1990a;10:996-1003.

75. Shors TJ, Chua C, Falduto J. Sex differences and opposite effects of stress on dendritic spine density in the male versus female hippocampus. J Neurosci. 2001a;21:6292-7.

76. Juraska JM, Fitch JM, Henderson C, Rivers N. Sex differences in the dendritic branching of dentate granule cells following differential experience. Brain Res. 1985;333:73-80. This is the first study demonstrating sex differences in the morphology of dentate granule neurons in response to environmental.

77. Maccari S, Krugers HJ, Morley-Fletcher S, Szyf M, Brunton PJ. The consequences of early-life adversity: neurobiological, behavioural and epigenetic adaptations. J Neuroendocrinol. 2014;26:707-23.

78. Loi M, Mossink JC, Meerhoff GF, Den Blaauwen JL, Lucassen PJ, Joëls M. Effects of early-life stress on cognitive function and hippocampal structure in female rodents. Neuroscience. 2017;342:101-19.

79. Guadagno A, Wong TP, Walker CD. Morphological and functional changes in the preweaning basolateral amygdala induced by early chronic stress associate with anxiety and fear behavior in adult male, but not female rats. Prog Neuropsychopharmacol Biol Psychiatry. 2018;81:25-37.

80. Maren S, Oca BDe, Fanselow MS. Sex differences in hippocampal long-term potentiation (LTP) and Pavlovian fear conditioning in rats: positive correlation between LTP and contextual learning. Brain Res. 1994;661:25-34.

81. Monfort $\mathrm{P}$, Gomez-Gimenez B, Llansola M, Felipo V. Gender differences in spatial learning, synaptic activity, and long-term potentiation in the hippocampus in rats: molecular mechanisms. ACS Chem Neurosci. 2015;6:1420-7.

82. Yang DW, Pan B, Han TZ, Xie W. Sexual dimorphism in the induction of LTP: Critical role of tetanizing stimulation. Life Sci. 2004:75:119-27.

83. Harte-Hargrove LC, Varga-Wesson A, Duffy AM, Milner TA, Scharfman HE. Opioid receptor-dependent sex differences in synaptic plasticity in the hippocampal mossy fiber pathway of the adult rat. J Neurosci. 2015;35:1723-38.

84. Qi X, Zhang K, Xu T, Yamaki VN, Wei Z, Huang M, et al. Sex differences in longterm potentiation at temporoammonic-CA1 synapses: potential implications for memory consolidation. PLoS ONE. 2016;11:1-18. This is the first study demonstrating that sex differences in AMPA/NMDA receptor composition influences on the sex differences in late-LTP of the CA1 pyramidal neurons.

85. Tan M, Tan U. Sex difference in susceptibility to epileptic seizures in rats: importance of estrous cycle. J Neurosci. 2001;108:175-91.

86. Terasawa E, Timiras PS. Electrical activity during the estrous cycle of the rat: cyclic changes in limbic structures. Endocrinology. 1968;83:207.

87. Oberlander JG, Woolley CS. 17-estradiol acutely potentiates glutamatergic synaptic transmission in the hippocampus through distinct mechanisms in males and females. J Neurosci. 2016;36:2677-90. This is the first study elucidating the cellular mechanism of enhancing effects of estradiol on neural excitability of the hippocampal neurons, in which estradiol enhances long- term potentiation through different estrogen receptors between males and females.

88. Scharfman HE, MacLusky NJ. Sex differences in hippocampal area CA3 pyramidal cells. J Neurosci Res. 2017;95:563-75.

89. Scharfman HE. Hyperexcitability in combined entorhinal/hippocampal slices of adult rat after exposure to brain-derived neurotrophic factor. J Neurophysiol. 1997;78:1082-95.

90. Scharfman HE, Mercurio TC, Goodman JH, Wilson MA, MacLusky NJ. Hippocampal excitability increases during the estrous cycle in the rat: a potential role for brain-derived neurotrophic factor. J Neurosci. 2003;23:11641-52.

91. Duarte-Guterman P, Yagi S, Chow C, Galea LAM. Hippocampal learning, memory, and neurogenesis: effects of sex and estrogens across the lifespan in adults. Horm Behav. 2015;74:37-52.

92. Nakashiba T, Cushman JD, Pelkey KA, Renaudineau S, Buhl DL, McHugh TJ, et al. Young dentate granule cells mediate pattern separation, whereas old granule cells facilitate pattern completion. Cell. 2012;149:188-201. The first study with determining the age of adult-born neurons dependent roles for pattern separation and pattern completion in male mice.

93. Snyder JS, Soumier A, Brewer M, Pickel J, Cameron HA. Adult hippocampal neurogenesis buffers stress responses and depressive behaviour. Nature. 2011;476:458-61.

94. Clelland CD, Choi M, Romberg C, Clemenson GD, Fragniere A, Tyers $P$, et al. A functional role for adult hippocampal neurogenesis in spatial pattern separation. Science. 2009;325:210-3. One of the first studies to show that adult neurogenesis in the hippocampus was required for pattern separation.

95. Shors TJ, Miesegaes G, Beylin A, Zhao M, Rydel T, Gould E. Neurogenesis in the adult is involved in the formation of trace memories. Nature. 2001b;410:372-6.

96. Denny CA, Burghardt NS, Schachter DM, Hen R, Drew MR. 4- To 6-week-old adult-born hippocampal neurons influence novelty-evoked exploration and contextual fear conditioning. Hippocampus. 2012;22:1188-201.

97. Drew MR, Denny CA, Hen R. Arrest of adult hippocampal neurogenesis in mice impairs single- but not multiple-trial contextual fear conditioning. Behav Neurosci. 2010;124:446-54.

98. Akers KG, Akers KG, Martinez-canabal A, Restivo L, Yiu AP, De Cristofaro A, et al. Hippocampal neurogenesis regulates forgetting during adulthood and infancy. Science. 2014;344:598-602. The first direct evidence that adult neurogenesis in the hippocampus was related to forgetting.

99. Kitamura T, Saitoh Y, Takashima N, Murayama A, Niibori Y, Ageta H, et al. Adult neurogenesis modulates the hippocampus-dependent period of associative fear memory. Cell. 2009;139:814-27.

100. Epp JR, Silva Mera R, Köhler S, Josselyn SA, Frankland PW. Neurogenesismediated forgetting minimizes proactive interference. Nat Commun. 2016;7:10838.

101. Snyder JS, Hong NS, McDonald RJ, Wojtowicz JM. A role for adult neurogenesis in spatial long-term memory. Neuroscience. 2005;130:843-52. This is an important study as it indicates that reducing neurogenesis in the dentate gyrus of male rats does not impair Morris Water Maze acquisition or immediate memory, but four weeks later, the rats were impaired in retention of spatial memory. Most studies do not examine long-term memory so this was a pivotal finding adding more information to how new neurons contribute to spatial memory.

102. Garthe A, Roeder I, Kempermann G. Mice in an enriched environment learn more flexibly because of adult hippocampal neurogenesis. Hippocampus. 2016;26:261-71.

103. Kalm M, Karlsson N, Nilsson MKL, Blomgren K. Loss of hippocampal neurogenesis, increased novelty-induced activity, decreased home cage activity, and impaired reversal learning one year after irradiation of the young mouse brain. Exp Neurol. 2013;247:402-9.

104. Seib DR, Chahley E, Princz-Lebel O, Snyder JS. Intact memory for local and distal cues in male and female rats that lack adult neurogenesis. PLoS ONE. 2018;13: e0197869.

105. Sliwowska JH, Barker JM, Barha CK, Lan N, Weinberg J, Galea LAM. Stressinduced suppression of hippocampal neurogenesis in adult male rats is altered by prenatal ethanol exposure. Stress. 2010;13:301-13.

106. Uban KA, Sliwowska JH, Lieblich S, Ellis LA, Yu WK, Weinberg J, et al. Prenatal alcohol exposure reduces the proportion of newly produced neurons and glia in the dentate gyrus of the hippocampus in female rats. Horm Behav. 2010;58:835-43.

107. Galea LAM, McEwen BS. Sex and seasonal differences in the rate of cell proliferation in the dentate gyrus of adult wild meadow voles. Neuroscience. 1999:89:955-64.

108. Westenbroek C, Den Boer JA, Veenhuis M, Ter Horst GJ. Chronic stress and social housing differentially affect neurogenesis in male and female rats. Brain Res Bull. 2004;64:303-8. 
109. Yagi S, Chow C, Lieblich SE, Galea LAM. Sex and strategy use matters for pattern separation, adult neurogenesis, and immediate early gene expression in the hippocampus. Hippocampus. 2016;101:87-101. This study is the first study demonstrating sex differences favouring male rats in the spatial pattern separation and in adult neurogenesis, in a learning strategy dependent manner.

110. Falconer EM, Galea LAM. Sex differences in cell proliferation, cell death and defensive behavior following acute predator odor stress in adult rats. Brain Res. 2003;975:22-36. One of the earliest studies to indicate a sex differences in neurogenesis in response to stress in adult rodents.

111. Spritzer MD, Panning AW, Engelman SM, Prince WT, Casler AE, Georgakas JE, et al. Seasonal and sex differences in cell proliferation, neurogenesis, and cell death within the dentate gyrus of adult wild-caught meadow voles. Neuroscience. 2017;360:155-65.

112. Lagace DC, Fischer SJ, Eisch AJ. Gender and endogenous levels of estradiol do not influence adult hippocampal neurogenesis in mice. Hippocampus. 2007;17:175-80.

113. Amrein I, Slomianka L, Poletaeva II, Bologova NV, Lipp HP. Marked species and age-dependent differences in cell proliferation and neurogenesis in the hippocampus of wild-living rodents. Hippocampus. 2004;14:1000-10.

114. Tzeng $\mathrm{W}-\mathrm{Y}$, Chen L-H, Cherng CG, Tsai Y-N, Yu L. Sex differences and the modulating effects of gonadal hormones on basal and the stressor-decreased newly proliferative cells and neuroblasts in dentate gyrus. Psychoneuroendocrinology. 2014;42:24-37.

115. Lee TTY, Wainwright SR, Hill MN, Galea LAM, Gorzalka BB. Sex, drugs, and adult neurogenesis: sex-dependent effects of escalating adolescent cannabinoid exposure on adult hippocampal neurogenesis, stress reactivity, and amphetamine sensitization. Hippocampus. 2014;24:280-92.

116. Barker JM, Galea LAM. Repeated estradiol administration alters different aspects of neurogenesis and cell death in the hippocampus of female, but not male, rats. Neuroscience. 2008;152:888-902.

117. Dalla C, Papachristos EB, Whetstone AS, Shors TJ. Female rats learn trace memories better than male rats and consequently retain a greater proportion of new neurons in their hippocampi. Proc Natl Acad Sci USA. 2009;106:2927-32. The first study to indicate that sex differences in learning was related to sex differences in the impact of that learning on neurogenesis in the hippocampus.

118. Hillerer KM, Neumann ID, Couillard-Despres S, Aigner L, Slattery DA. Sexdependent regulation of hippocampal neurogenesis under basal and chronic stress conditions in rats. Hippocampus. 2013;23:476-87.

119. Swift-Gallant A, Duarte-Guterman P, Hamson DK, Ibrahim M, Monks DA, Galea LAM. Neural androgen receptors affect the number of surviving new neurons in the adult dentate gyrus of male mice. J Neuroendocrinol. 2018;e12578:https:// doi.org/10.1111/jne.12578.

120. Hamson DK, Wainwright SR, Taylor JR, Jones BA, Watson NV, Galea LAM. Androgens increase survival of adult-born neurons in the dentate gyrus by an androgen receptor-dependent mechanism in male rats. Endocrinology. 2013;154:3294-304.

121. Mahmoud R, Wainwright SR, Galea LAM. Sex hormones and adult hippocampal neurogenesis: Regulation, implications, and potential mechanisms. Front Neuroendocrinol. 2016:41:129-52.

122. Kambo JS, Galea LAM. Activational levels of androgens influence risk assessment behaviour but do not influence stress-induced suppression in hippocampal cell proliferation in adult male rats. Behav Brain Res. 2006;175:263-70.

123. Naninck EFG, Hoeijmakers L, Kakava-Georgiadou N, Meesters A, Lazic SE, Lucassen PJ, et al. Chronic early life stress alters developmental and adult neurogenesis and impairs cognitive function in mice. Hippocampus. 2015;25:309-28.

124. Gobinath AR, Workman JL, Chow C, Lieblich SE, Galea LA. Maternal postpartum corticosterone and fluoxetine differentially affect adult male and female offspring on anxiety-like behavior, stress reactivity, and hippocampal neurogenesis. Neuropharmacology. 2016;101:165-78.

125. Gobinath AR, Workman JL, Chow C, Lieblich SE, Galea LAM. Sex-dependent effects of maternal corticosterone and SSRI treatment on hippocampal neurogenesis across development. Biol Sex Differ. 2017b;8:1-13.

126. Oomen CA, Girardi CEN, Cahyadi R, Verbeek EC, Krugers $H$, Joëls $M$, et al. Opposite effects of early maternal deprivation on neurogenesis in male versus female rats. PLoS ONE. 2009;4:e3675.

127. Barha CK, Brummelte S, Lieblich SE, Galea LAM. Chronic restraint stress in adolescence differentially influences hypothalamic-pituitary-adrenal axis function and adult hippocampal neurogenesis in male and female rats. Hippocampus. 2011;21:1216-27.

128. Gobinath AR, Mahmoud R, Galea LAM. Influence of sex and stress exposure across the lifespan on endophenotypes of depression: focus on behavior, glucocorticoids, and hippocampus. Front Neurosci. 2015:9:1-18.
129. Chow C, Epp JR, Lieblich SE, Barha CK, Galea LAM. Sex differences in neurogenesis and activation of new neurons in response to spatial learning and memory. Psychoneuroendocrinology. 2013;38:1236-50. One of first studies to examine sex differences in immediate early gene expression in new neurons in association with learning ability.

130. Epp JR, Spritzer MD, Galea LAM. Hippocampus-dependent learning promotes survival of new neurons in the dentate gyrus at a specific time during cell maturation. Neuroscience. 2007;149:273-85.

131. Lawton CA. Gender differences in way-finding strategies: relationship to spatial ability and spatial anxiety. Sex Roles. 1994;30:765-79.

132. Silverman I, Choi J. Non-Euclidean navigational strategies of women: compensatory response or evolved dimorphism? Evol Psychol. 2006;4:75-84.

133. Dabbs JM, Chang E-L, Strong RA, Milun R. Spatial ability, navigation strategy, and geographic knowledge among men and women. Evol Hum Behav. 1998; 19:89-98.

134. Korol DL, Malin EL, Borden KA, Busby RA, Couper-Leo J. Shifts in preferred learning strategy across the estrous cycle in female rats. Horm Behav. 2004;45:330-8. One of first studies examining sex difference and effect of estrous cycle on learning strategy of rats.

135. Grissom EM, Hawley WR, Hodges KS, Fawcett-Patel JM, Dohanich GP. Biological sex influences learning strategy preference and muscarinic receptor binding in specific brain regions of prepubertal rats. Hippocampus. 2013;23:313-22.

136. Hawley WR, Grissom EM, Barratt HE, Conrad TS, Dohanich GP. The effects of biological sex and gonadal hormones on learning strategy in adult rats. Physiol Behav. 2012;105:1014-20.

137. Maguire EA, Burgess N, Donnett JG, Frackowiak RSJ, Maguire EA, Burgess N, et al. Knowing where and getting there: a human navigation network. Science. 2017;280:921-4.

138. McDonald RJ, White NM. A triple dissociation of memory systems: hippocampus, amygdala, and dorsal striatum. Behav Neurosci. 1993;107:3-22.

139. laria G, Petrides M, Dagher A, Pike B, Bohbot VD. Cognitive strategies dependent on the hippocampus and caudate nucleus in human navigation: variability and change with practice. J Neurosci. 2003;23:5945-52.

140. Andersen NE, Dahmani L, Konishi K, Bohbot VD. Eye tracking, strategies, and sex differences in virtual navigation. Neurobiol Learn Mem. 2012;97:81-9.

141. Galea LAM, Kimura D. Sex differences in route-learning. Personal Individ Differ. 1993;14:53-65.

142. Williams CL, Barnett AM, Meck WH. Organizational effects of early gonadal secretions on sexual differentiation in spatial memory. Behav Neurosci. 1990;104:84-97.

143. Cherney ID, Brabec CM, Runco DV. Mapping out spatial ability: sex differences in way-finding navigation. Percept Mot Skills. 2008;107:747-60.

144. Spritzer MD, Fox EC, Larsen GD, Batson CG, Wagner BA, Maher J. Testosterone influences spatial strategy preferences among adult male rats. Horm Behav. 2013;63:800-12.

145. Keeley RJ, Tyndall AV, Scott GA, Saucier DM. Sex difference in cue strategy in a modified version of the Morris water task: correlations between brain and behaviour. PLoS ONE. 2013;8:e69727.

146. Moradpour F, Naghdi N, Fathollahi Y, Javan M, Choopani S, Gharaylou Z. Prepubertal castration improves spatial learning during mid-adolescence in rats. Prog Neuropsychopharmacol Biol Psychiatry. 2013;46:105-12.

147. Yagi S, Drewczynski D, Wainwright SR, Barha CK, Hershorn O, Galea LAM. Sex and estrous cycle differences in immediate early gene activation in the hippocampus and the dorsal striatum after the cue competition task. Horm Behav. 2017;87:69-79.

148. Linn MC, Petersen AC. Emergence and characterization of sex differences in spatial ability: a meta-analysis. Soc Res Child Dev. 2016;56:1479-98.

149. Voyer D, Voyer S, Bryden MP. Magnitude of sex differences in spatial abilities: a meta-analysis and consideration of critical variables. Psychol Bull. 1995;117:250-70.

150. Jonasson Z. Meta-analysis of sex differences in rodent models of learning and memory: a review of behavioral and biological data. Neurosci Biobehav Rev. 2005;28:811-25.

151. Chamizo VD, Artigas AA, Sansa J, Banterla F. Gender differences in landmark learning for virtual navigation: the role of distance to a goal. Behav Process. 2011;88:20-6.

152. Button KS, loannidis JP, Mokrysz C, Nosek BA, Flint J, Robinson ES, et al. Power failure: why small sample size undermines the reliability of neuroscience. Nat Rev Neurosci. 2013;14:365-76.

153. Hvoslef-Eide M, Nilsson SR, Saksida LM, Bussey TJ. Cognitive translation using the rodent touchscreen testing approach. Curr Top Behav Neurosci. 2016;28:423-47.

154. Perrot-Sinal TS, Kostenuik MA, Ossenkopp KP, Kavaliers M. Sex differences in performance in the Morris water maze and the effects of initial nonstationary hidden platform training. Behav Neurosci. 1996;110:1309-20. 
155. Beiko J, Lander R, Hampson E, Boon F, Cain DP. Contribution of sex differences in the acute stress response to sex differences in water maze performance in the rat. Behav Brain Res. 2004;151:239-53.

156. Engelmann M, Ebner K, Landgraf R, Wotjak CT. Effects of Morris water maze testing on the neuroendocrine stress response and intrahypothalamic release of vasopressin and oxytocin in the rat. Horm Behav. 2006;50:496-501.

157. Galea LA, Kavaliers M, Ossenkopp KP, Hampson E. Gonadal hormone levels and spatial learning performance in the Morris water maze in male and female meadow voles, Microtus pennsylvanicus. Horm Behav. 1995;29:106-25.

158. Barha CK, Pawluski JL, Galea LAM. Maternal care affects male and female offspring working memory and stress reactivity. Physiol Behav. 2007;92:939-50.

159. Bayer J, Gläscher J, Finsterbusch J, Schulte LH, Sommer T. Linear and inverted Ushaped dose-response functions describe estrogen effects on hippocampal activity in young women. Nat Commun. 2018;9:1220.

160. Hampson E. Estrogen-related variations in human spatial and articulatory-motor skills. Psychoneuroendocrinology. 1990;15:97-111. One of the first studies to show a double dissociation in cognitive performance across the menstrual cycle during menses and the pre-ovulatory surge, in a number of tasks. Hampson found spatial performance improved but fine motor skills worsened during menses while the reverse pattern was observed during the preovulatory surge.

161. Viau V, Meaney MJ. Basal and stress hypothalamic pituitary adrenal activity in cycling and ovariectomized steroid treated rats. Endocrinology. 1992;131:1261-9.

162. Bowman RE, Zrull MC, Luine VN. Chronic restraint stress enhances radial arm maze performance in female rats. Brain Res. 2001;904:279-89.

163. Wood GE, Shors TJ. Stress facilitates classical conditioning in males, but impairs classical conditioning in females through activational effects of ovarian hormones. Proc Natl Acad Sci. 1998;95:4066-71.

164. Luine V. Sex differences in chronic stress effects on memory in rats. Stress. 2002;5:205-16.

165. Hodes GE, Pfau ML, Purushothaman I, Ahn HF, Golden SA, Christoffel DJ, et al Sex differences in nucleus accumbens transcriptome profiles associated with susceptibility versus resilience to subchronic variable stress. J Neurosci. 2015;35:16362-76. This is the first study indicating that elucidating the association between transcriptome analysis in the nucleus accumbens and sex differences in stress vulnerability.

166. Arnold AP, Lusis AJ. Understanding the sexome: measuring and reporting sex differences in gene systems. Endocrinology. 2012;153:2551-5.

167. Labonté B, Engmann O, Purushothaman I, Menard C, Wang J, Tan C, et al. Sexspecific transcriptional signatures in human depression. Nat Med. 2017;23:1102-11. This is a comprehensive transcriptome analysis elucidating sex differences in the gene expression in human brains with major depressive disorder.

168. Mangold CA, Wronowski B, Du M, Masser DR, Hadad N, Bixler GV, et al. Sexually divergent induction of microglial-associated neuroinflammation with hippocampal aging. J Neuroinflamm. 2017;14:141.

169. Guebel DV, Torres NV. Sexual dimorphism and aging in the human hyppocampus: identification, validation, and impact of differentially expressed genes by factorial microarray and network analysis. Front Aging Neurosci. 2016;8:229.

170. Hanamsagar R, Alter MD, Block CS, Sullivan H, Bolton JL, Bilbo SD. Generation of a microglial developmental index in mice and in humans reveals a sex difference in maturation and immune reactivity. Glia. 2017;65:1504-20.

171. Bundy JL, Vied C, Nowakowski RS. Sex differences in the molecular signature of the developing mouse hippocampus. BMC Genom. 2017;18:1-17.

172. Vied C, Ray S, Badger CD, Bundy JL, Arbeitman MN, Nowakowski RS. Transcriptomic analysis of the hippocampus from six inbred strains of mice suggests a basis for sex-specific susceptibility and severity of neurological disorders. J Comp Neurol. 2016;524:2696-710.

173. Guzowski JF, Setlow B, Wagner EK, McGaugh JL. Experience-dependent gene expression in the rat hippocampus after spatial learning: a comparison of the immediate-early genes Arc, c- fos, and zif268. J Neurosci. 2001;21:5089-98.

174. Jones MW, Errington ML, French PJ, Fine A, Bliss TV, Garel S, et al. A requirement for the immediate early gene Zif268 in the expression of late LTP and long-term memories. Nat Neurosci. 2001;4:289-96.

175. Wisden W, Errington ML, Williams S, Dunnett SB, Waters C, Hitchcock D, et al. Differential expression of immediate early genes in the hippocampus and spinal cord. Neuron. 1990;4:603-14.
176. Douglas RM, Dragunow M, Robertson HA. High-frequency discharge of dentate granule cells, but not long-term potentiation, induces c-fos protein. Brain Res. 1988;464:259-62.

177. Penke Z, Morice E, Veyrac A, Gros A, Chagneau C, Samson N et al. Plasticity and long-term spatial recognition memory Zif268 / Egr1 gain of function facilitates hippocampal synaptic plasticity and long-term spatial recognition memory. Phil Trans R Soc B Biol Sci. 2014;369:20130159.

178. Petersohn D, Schoch S, Brinkmann DR, Thiel G. The human synapsin II gene promoter: possible role for the transcription factors zif268/EGR-1, polyoma enhancer activator 3, and AP2. J Biol Chem. 1995;270:24361-9.

179. Moser MB, Moser El, Forrest E, Andersen P, Morris RG. Spatial learning with a minislab in the dorsal hippocampus. Proc Natl Acad Sci. 1995;92:9697-701.

180. Lonergan ME, Gafford GM, Jarome TJ, Helmstetter FJ. Time-dependent expression of arc and Zif268 after acquisition of fear conditioning. Neural Plast. 2010;2010:8-11. This is one of few study reporting time courses of immediate early genes Arc and zif268 protein expression, which indicates zif268 expression reaches the peak earlier than Arc protein expression.

181. Barros VN, Mundim M, Galindo LT, Bittencourt S, Porcionatto M, Mello LE. The pattern of c-Fos expression and its refractory period in the brain of rats and monkeys. Front Cell Neurosci 2015;9:1-8.

182. Kessler RC, Petukhova M, Sampson NA, Zaslavsky AM, Wittchen H-U. Twelvemonth and lifetime prevalence and lifetime morbid risk of anxiety and mood disorders in the United States. Int J Methods Psychiatr Res. 2012;21: 169-84.

183. Breslau N, Davis GC, Andreski P, Peterson EL, Schultz LR. Sex differences in posttraumatic stress disorderr. Arch Gen Psychiatry. 1997;54:1044-8.

184. Meulders A, Vansteenwegen D, Vlaeyen JWS. Women, but not men, report increasingly more pain during repeated (un)predictable painful electrocutaneous stimulation: evidence for mediation by fear of pain. Pain. 2012;153:1030-41.

185. Keiser AA, Turnbull LM, Darian MA, Feldman DE, Song I, Tronson NC. Sex differences in context fear generalization and recruitment of hippocampus and amygdala during retrieval. Neuropsychopharmacology. 2017;42:397-407. This study demonstrates that the hippocampus and amygdala compete with each other during fear related memory retrieval, and sex modulates the competition between the two regions.

186. Lynch JJ, Cullen PK, Jasnow AM, Riccio DC. Sex differences in the generalization of fear as a function of retention intervals. Learn Mem. 2013;20:628-32.

187. Gresack JE, Schafe GE, Orr PT, Frick KM. Sex differences in contextual fear conditioning are associated with differential ventral hippocampal extracellular signal-regulated kinase activation. Neuroscience. 2009;159:451-67.

188. Matsuda S, Matsuzawa D, Ishii D, Tomizawa H, Sutoh C, Shimizu E. Sex differences in fear extinction and involvements of extracellular signal-regulated kinase (ERK). Neurobiol Learn Mem. 2015;123:117-24.

189. Voulo ME, Parsons RG. Response-specific sex difference in the retention of fear extinction. Learn Mem. 2017;24:245-51.

190. Barker JM, Galea LA. Males show stronger contextual fear conditioning than females after context pre-exposure. Physiol Behav. 2010;99:82-90.

191. Gruene TM, Flick K, Stefano A, Shea SD, Shansky RM. Sexually divergent expression of active and passive conditioned fear responses in rats. $\boldsymbol{A}$ study showing that female rats show distinctly different active responses to fear memory, unlike male rats. eLife 2015;4:e11352.

192. Chen LS, Tzeng WY, Chuang JY, Cherng CG, Gean PW, Yu L. Roles of testosterone and amygdaloid LTP induction in determining sex differences in fear memory magnitude. Horm Behav. 2014;66:498-508.

193. Gruene TM, Roberts E, Thomas V, Ronzio A, Shansky RM. Sex-specific neuroanatomical correlates of fear expression in prefrontal-amygdala circuits. Biol Psychiatry. 2015;78:186-93.

194. Barha CK, Hsiung G-YR, Best JR, Davis JC, Eng JJ, Jacova C, et al. Sex difference in aerobic exercise efficacy to improve cognition in older adults with vascular cognitive impairment: secondary analysis of a randomized controlled. Trial J Alzheimer's Dis. 2017:60:1-13.

195. Varma VR, Tang X, Carlson MC. Hippocampal sub-regional shape and physical activity in older adults. Hippocampus. 2016;26:1051-60.

196. Nieuwenhuis S, Forstmann BU, Wagenmakers EJ. Erroneous analyses of interactions in neuroscience: a problem of significance. Nat Neurosci. 2011;14:1105-7. 